\title{
Transparency and Liquidity: A Controlled Experiment on Corporate Bonds
}

\author{
Michael A. Goldstein \\ Babson College
}

Edith S. Hotchkiss

Boston College

\author{
Erik R. Sirri \\ Babson College
}

\begin{abstract}
This article reports the results of an experiment designed to assess the impact of lastsale trade reporting on the liquidity of BBB corporate bonds. Overall, adding transparency has either a neutral or a positive effect on liquidity. Increased transparency is not associated with greater trading volume. Except for very large trades, spreads on newly transparent bonds decline relative to bonds that experience no transparency change. However, we find no effect on spreads for very infrequently traded bonds. The observed decrease in transaction costs is consistent with investors' ability to negotiate better terms of trade once they have access to broader bond-pricing data. (JEL codes: G14, G18, G23, G24, G28)
\end{abstract}

\begin{abstract}
Although larger than the market for US Government or municipal bonds, the corporate bond market historically has been one of the least transparent securities markets in the United States, with neither pretrade nor posttrade transparency. Corporate bonds trade primarily over-the-counter, and until recently, no centralized mechanism existed to collect and disseminate posttransaction information. This structure changed on July 1, 2002, when the National Association of Securities Dealers (NASD) began a program of increased posttrade transparency for corporate bonds, known as the Trade Reporting and Compliance Engine (TRACE) system. As part of this structural change, only a selected subset of bonds initially was subject to public dissemination of trade information. The resulting experiment enables us to observe the effects of increased posttrade transparency on market liquidity in a controlled setting.
\end{abstract}

\footnotetext{
The authors are grateful to David Pedersen for extensive research assistance. We thank Amy Edwards, Amar Gande, Jean Helwege, Kenneth Kavajecz, Marc Lipson, Michael Piwowar, Patrik Sandas, Arthur Warga, and seminar participants at the Bank of Canada, Boston College, Queen's University, University of Arizona, University of Mississippi, University of Virginia, and the 2006 American Finance Association Annual Meetings for helpful discussions. All remaining errors are those of the authors.
}

(C) The Author 2006. Published by Oxford University Press on behalf of The Society for Financial Studies. All rights reserved. For permissions, please email: journals.permissions@oxfordjournals.org. 
With the July 2002 introduction of TRACE, all NASD members were required for the first time to report prices, quantities, and other information for all secondary market transactions in corporate bonds. ${ }^{1}$ Some market participants and regulators initially were concerned that public dissemination of this data for smaller and lower grade bonds might have an adverse impact on liquidity. Therefore, as of July 2002, the trade information collected by the NASD was publicly disseminated only for investment grade issues (bonds rated BBB and above) with issue sizes greater than $\$ 1$ billion. Dissemination of trade information for all other bonds was to be phased in later, pending a series of studies of the likely impact of increased transparency.

The first study, which is the subject of this article, involved a controlled experiment designed to test the impact of transparency on liquidity for the BBB bond market. Using nonpublic TRACE trade data for all BBB bonds from July 2002 to February 2003, we selected 120 bonds for which the NASD subsequently began public dissemination of trade data. These bonds fell into two groups, 90 more actively traded bonds and 30 relatively inactive bonds, enabling us to examine transparency issues across the liquidity spectrum. ${ }^{2}$ We simultaneously identified a control sample of nondisseminated bonds. This provided us the opportunity to conduct a true experiment by altering the transparency properties of some of these securities. By intertemporally comparing the trades of the disseminated bonds with themselves before and after they were made transparent, and by comparing the trades of the disseminated bonds with those of the matching but nondisseminated bonds, we, in our experiment, gauge the effects of transparency on bond liquidity in a systematic and controlled framework.

The NASD began public dissemination of trades in the 120 selected BBB bonds on April 14, 2003. We were provided not only with data for the 120 disseminated bonds but the entire universe of BBB-rated corporate bonds, whether disseminated or not. After applying some filters, the data set we analyze for our study consists of all trades from July 8, 2002 to February 27, 2004 for 4888 BBB-rated corporate bonds that have an original issue size between $\$ 10$ million and $\$ 1$ billion.

\footnotetext{
${ }^{1}$ Before TRACE, transaction information for high-yield bonds was collected by the NASD under the Fixed Income Pricing System (FIPS), but only hourly trading summaries for a sample of 50 high-yield bonds were publicly disseminated. See Hotchkiss and Ronen (2002) and Alexander, Edwards, and Ferri (2000) for further description of the FIPS reporting requirements.

${ }^{2}$ As noted by Federal Register (2002), the NASD was charged with having independent economists (the authors of this article) design an experiment to test the effects of transparency on corporate bond liquidity. We were originally mandated to choose only $90 \mathrm{BBB}$ bonds to begin dissemination. However, including too many infrequently traded bonds in our mandated 90-bond sample would potentially compromise the power of our tests. Therefore, we requested that an additional, separate group of 30 thinly traded bonds be made subject to dissemination as well. See Federal Register (2003) for more details.
} 
We find that depending on trade size, increased transparency has either a neutral or a positive effect on market liquidity, as measured by trading volume or estimated bid-ask spreads. Measures of trading activity, such as daily trading volume and number of transactions per day, show no relative increase, indicating that increased transparency does not lead to greater trading interest in our sample period. The relatively long (10 months) posttransparency period suggests that this lack of increased trading volume is not due to the newness of the market changes. For all but the largest trade size group, spreads decrease for bonds whose prices become transparent by more than the amount that spreads decline for our control bonds. This effect is strongest for small and intermediate trade sizes: for trades between 101 and 250 bonds, relative to their controls, spreads on the 90 disseminated bonds fall by either 38 or 22 basis points (per $\$ 100$ face value) more, depending on the spread estimation method. The decrease in transaction costs for such trades is consistent with investors' ability to negotiate better terms of trade with dealers once the investors have access to broader bond-pricing data. We do not find a significant change in spreads for very thinly traded bonds. Thus, overall, we find that increased transparency has a neutral or a positive effect on liquidity.

Because pretrade quote data do not exist for this market, we estimate the impact of transparency on spreads using two different techniques. We first measure spreads directly by measuring the round-trip cost of a dealer purchase from a customer followed by a sale of that bond by the same dealer to another customer (a dealer round-trip or DRT) within a specified time period. This DRT method is similar to that used by Green, Hollifield, and Schurhoff (2004) and Biais and Green (2005) in their studies of municipal bonds, except that we use additional information provided in our data set which identifies individual dealers (using an anonymous code for each dealer). A distinct advantage of this approach is that it provides a measure of bond spreads that is simple to interpret and is not dependent on assumptions used to model spreads.

Using this method, for all BBB bonds we find that for round-trips that occur within one day, spreads average $\$ 2.35$ (median $\$ 2.25$ ) per $\$ 100$ face value for trades up to 10 bonds. These costs fall to $\$ 0.50$ (median $\$ 0.31$ ) per $\$ 100$ for trades of 1000 bonds or more. For both the 90 disseminated bonds and their nondisseminated controls, we find for all trade size groups that customer transaction costs fall from the predissemination to postdissemination time period. ${ }^{3}$ However, for all but the largest trade size groups, transaction costs fall more for the 90 disseminated bonds than for their nondisseminated controls. In addition, our cross-sectional analysis,

\footnotetext{
${ }^{3}$ We do not include the additional 30 less active disseminated BBB bonds (and their controls) in these comparisons because of the relatively small number of observations of DRTs.
} 
which controls for additional bond characteristics affecting spreads, shows that spreads are lower when the bonds are disseminated, reaching a maximum decline of 67 basis points for intermediate size trades.

We also estimate spreads using a second methodology similar to that of Warga (1991) and Schultz (2001), based on regression estimates of the difference between transaction prices and the previous day's estimated bid price as reported by Reuters. The regression-based results, which utilize all trading data over this time period, support the results found using the more direct DRT method. For the 90 disseminated more actively traded bonds, transparency is associated with an additional decrease in costs, over and above market-wide changes; this decline is greatest for small trades of 10 bonds or less ( 60 basis points per $\$ 100$ face value), falls to a decline of 17.4 basis points for trades of up to 1000 bonds, and is insignificant for trade sizes greater than 1000 bonds. However, for the additional disseminated sample of 30 less active BBB bonds, we find no significant effect of transparency either overall or for any trade size group.

Our analyses are related to those in two other recent working papers. Using the TRACE data, Edwards, Harris, and Piwowar (2005) fit a timeseries model of transaction costs for individual bonds. They then use this model in a cross-sectional regression to explain determinants of transaction costs and conclude that transparency is associated with about a 10 basis point drop in spreads overall for bonds of all ratings (including BBB). Bessembinder, Maxwell, and Venkataraman (2005) estimate the impact of TRACE on trading costs using insurance company trades reported at the daily level to the National Association of Insurance Commissioners (NAIC). The NAIC data set permits the authors to evaluate the impact of transparency by examining costs relative to those estimated before the July 2002 start of TRACE. ${ }^{4}$ For the large institutional trades included in their data set, they conclude that there is a 12 to 14 basis point reduction in round-trip trade execution costs for bonds that become disseminated on TRACE.

An important difference of our work is that rather than focusing on the cross-sectional determinants of trading costs, we focus on the BBB transparency experiment. For all other investment grade credit ratings besides $\mathrm{BBB}$, all bonds of a given rating and issue size are either subject or not subject to dissemination under TRACE at a given time. The BBB market is the only case in which we can simultaneously observe bonds of the same credit rating and matched on characteristics such as issue size and trading activity, some of which are disseminated and some of which are not. Furthermore, both regulators and market participants believed the

\footnotetext{
${ }^{4}$ Hong and Warga (2000) and Chakravarty and Sarkar (2003) provide estimates of trading costs from the NAIC data set for an earlier time period. See also Chen, Lesmond, and Wei (2005) for discussion of liquidity measures for corporate bonds.
} 
market for the highest rated and very large issues, which are less information sensitive and also have more close substitutes, would not behave in the same manner as lower rated or smaller issues, hence the willingness to begin dissemination for bonds rated above BBB sooner. ${ }^{5}$ Over the time period we examine, trading in BBB bonds accounted for $37 \%$ of the number of trades and $33 \%$ of the face amount traded for all secondary market transactions in corporate bonds of any rating reported to TRACE.

Our article also differs from these articles in the methods used to estimate trading costs. For large trades, our median estimate of spreads for DRTs that occur within one day are close to the 27 basis point estimate reported by Schultz (2001). An advantage of the DRT measure is that it does not utilize any data external to the TRACE data or any econometric models for estimating prices for bonds that are infrequently traded. Our regressionbased spread estimates are somewhat higher, but the increase in magnitude can be partially explained by the presence of more extreme observations in the data. The methods we use allow us to disentangle any nonlinear effects, such as those due to overall trading frequency, which we find to be an important determinant of the impact of transparency.

From a theoretical perspective, the impact of transparency on market liquidity is ambiguous, as noted by Madhavan (1995), Pagano and Roell (1996), and Naik, Neuberger, and Viswanathan (1999). ${ }^{6}$ Greater transparency may reduce adverse selection and encourage uninformed investors to enter the trading arena. At the same time, it may change the economics of trading by market makers who supply liquidity. In a world with posttrade reporting, a market maker can be in a difficult bargaining position to unwind her inventory following a large trade, leading her to charge a premium for this risk. Bloomfield and O'Hara (1999) provide experimental evidence showing that opening spreads are larger but subsequent spreads are tighter when ex post transparency is enhanced. Resolving this debate empirically has been difficult because there are very few settings that in practice allow us to observe the impact of a change in transparency. ${ }^{7}$ The introduction of the TRACE system,

\footnotetext{
${ }^{5}$ The disseminated bonds considered by Edwards et al. (2005) and Bessembinder et al. (2005) include investment grade bonds with issue size over \$1 billion, which were disseminated upon the July 2002 start of TRACE, and the 50 high-yield bonds disseminated under TRACE to provide continuity for bonds previously reported under the FIPS system. The set of 50 high-yield bonds disseminated under TRACE were not selected randomly; bonds disseminated as of July 2002 under TRACE were already disseminated under FIPS (thus, we would observe the impact of the incremental transparency). In addition to the dissemination of the 120 selected BBB bonds on April 14, 2003, the NASD began dissemination of trade information for all bonds rated A and above with issue sizes over \$100 million on March 3, 2003.

${ }^{6}$ Biais, Glosten, and Spatt (2005) provide an overview of these arguments.

${ }^{7}$ A notable exception examining changes in posttrade transparency is the finding of Gemmill (1996), who finds that dealer spreads were not affected by changes in the trade disclosure delay for large trades on the London Stock Exchange (LSE). However, while the length of the delay was varied, posttrade transparency was not removed completely for that market. In further contrast to our study, pretrade transparency also existed for the LSE.
} 
and specifically the experiment we have structured using the BBB market, provides such an opportunity to observe these effects.

This article is organized as follows. Section 1 describes the TRACE system and the data used in the study. Section 2 considers the effect of transparency on trading frequency and volume. Section 3 analyzes the effect of increased transparency on bond spreads results using our two different estimation methods. Section 4 summarizes and concludes the article.

\section{Data Description and Design of the Experiment}

We analyze all secondary market trades in 4888 BBB-rated corporate bonds for the time period July 8, 2002 through February 27, 2004. Our data set includes all bond trades during this time, with the exception of a comparatively small amount of trading activity on the NYSE's Automated Bond System (ABS), which is not reported through TRACE. NASD (2004) estimates that $99.9 \%$ of trading is transacted over-thecounter and is therefore included in our data.

\subsection{Selection of bonds for dissemination and for nondisseminated control groups}

The selection of BBB bonds for dissemination under TRACE was based on transactions that occurred in the period from July 8, 2002 through January 31, 2003 (the selection period). Our selection process excluded convertible bonds, bonds from banks, and bonds with unusual features. We also eliminated BBB bonds with an issue size over $\$ 1$ billion, as their prices were already disseminated as of July 1, 2002, and bonds with an issue size less than $\$ 10$ million. Because Hotchkiss, Jostova, and Warga (2005) indicate that there is an abnormal amount of trading in the first few months following issuance, we did not include newly issued bonds. We also excluded bonds with less than one year remaining to maturity.

Because of concerns about the statistical power of our tests, we chose two groups of bonds for dissemination based on their frequency of trading in the selection period. First, we identified 90 pairs of bonds, matching on industry, trading activity (average trades per day) during the selection period, bond age, and time to maturity. We required that these bonds traded at least once per week on average during the selection period. As pairs of bonds were created, one bond was randomly chosen to be disseminated and the other was assigned to a nondisseminated control group (the "matching" control bonds). We then identified an additional sample of 30 thinly traded bonds for dissemination, requiring only that the bonds traded on average at least once every two weeks but less than once every two days on average during the selection period. Because the 30 thinly traded bonds trade so infrequently, we do not construct a 
bond-by-bond matched control sample for empirical analysis. ${ }^{8}$ In total, $120 \mathrm{BBB}$ bonds (90 actively traded and 30 thinly traded) were subject to dissemination under TRACE on April 14, 2003.

As Davies and Kim (2004) note, creating a control set from matching pairs is at times optimal, while at other times a larger control portfolio may be optimal. Using the matching approach, it is possible that results may be sensitive to the particular choice of bonds for the control portfolio. Using a broader control portfolio, however, will include more bonds that are quite dissimilar to those that are disseminated. Furthermore, given the substantially smaller number of observations, we do not construct a matched control sample for the 30 thinly traded bonds. Therefore, we use both approaches in our tests. For the 90 actively traded disseminated bonds, in addition to the matched control sample, we also construct a "nondisseminated control portfolio" consisting of bonds whose average number of trades per day is between the minimum and maximum observed for the 90 disseminated bonds in the period July 8, 2002 to January 31, 2003. This control portfolio consists of 2997 bonds, whose average daily trade count in the selection period ranges from 0.2105 to 24.8 .

We use a similar procedure to construct a control portfolio for the 30 thinly traded bonds. This produces a nondisseminated control portfolio consisting of 1704 bonds, whose average daily trade count in the selection period ranges from 0.1 to 0.4 . By comparing the 30 thinly traded bonds to their corresponding nondisseminated control portfolio, we obtain meaningful results for the effects of transparency on these bonds.

\subsection{Characteristics and trading activity of disseminated and control bonds}

Industry categories and other bond characteristics for each group of bonds, as well as for the full set of BBB bonds, are summarized in Table 1. The data for the full set of all BBB bonds indicate the dominance of financial firms in this market: over $44 \%$ of all bonds are issued by financial firms or subsidiaries, although many other industries are also represented. Subsequent results using control portfolios are insensitive to the removal of financial issuers from those portfolios. Table 1 also summarizes that (by construction) the matching nondisseminated bonds have the same distribution across industries as the 90 disseminated bonds.

Table 2 summarizes other bond traits that have been shown in previous studies to affect inferences concerning bond liquidity, as well as trading activity for the entire period from July 8, 2002 to February 27, 2004. By construction, the issue size, years to maturity, and age match closely for

\footnotetext{
${ }^{8}$ As previously described, for the 30-bond sample, we rely instead on our regression-based methodology using a portfolio of control bonds, which allows us to control for bond characteristics while providing a substantial increase in the number of observations.
} 


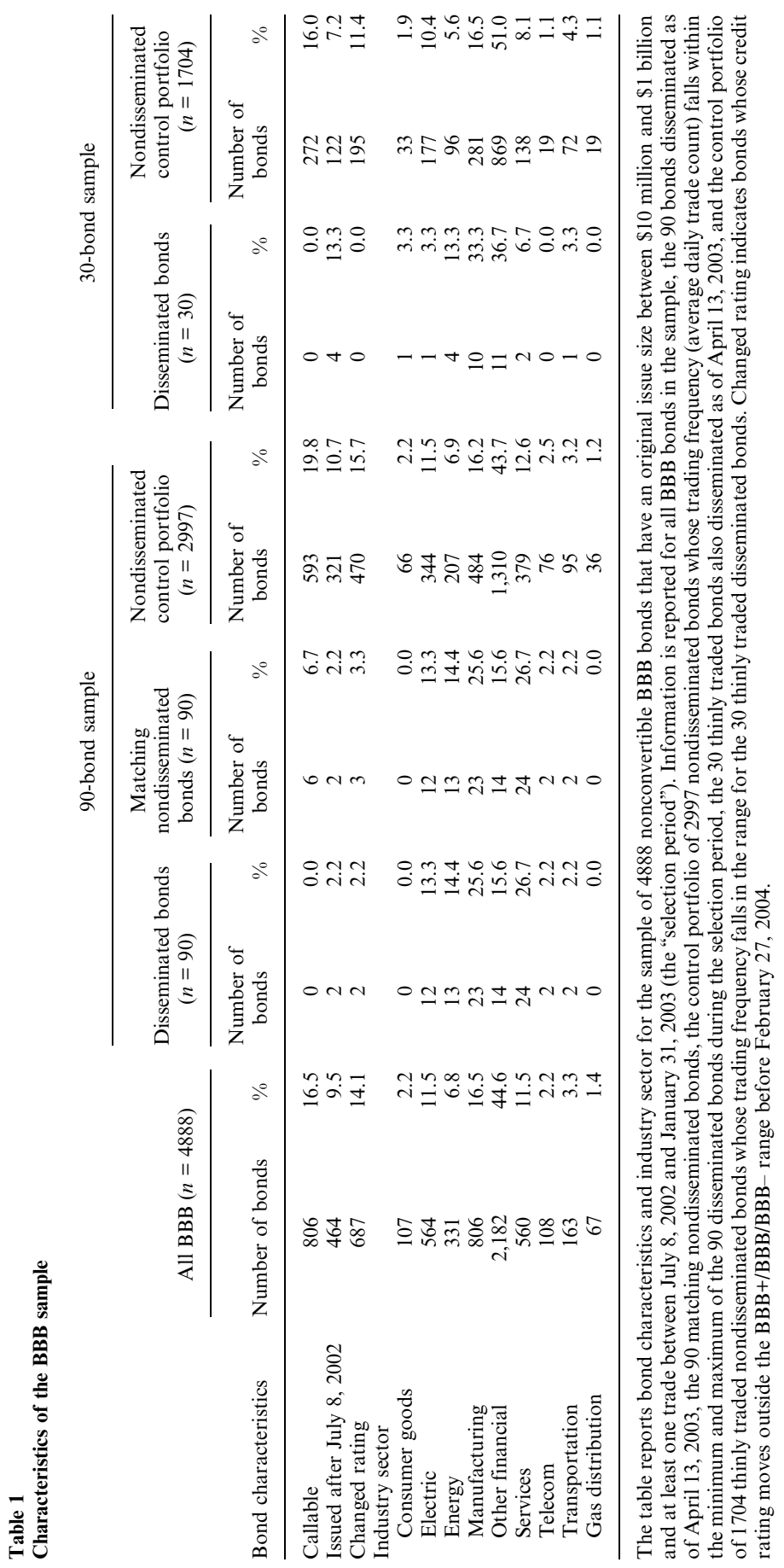




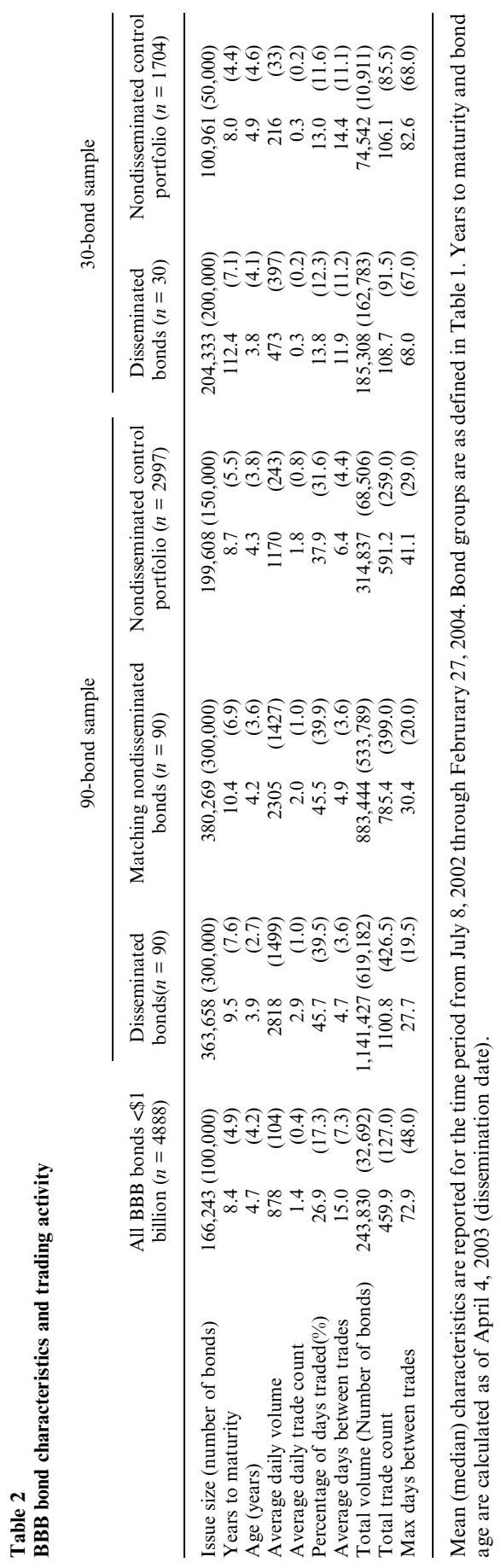


the 90 disseminated bonds and their 90 nondisseminated matchers. Because we do not match on these characteristics for the two large portfolios of nondisseminated bonds, bonds in these control portfolios tend to have a smaller original issue size and somewhat fewer years remaining to maturity.

It is evident from Table 2 that the bonds in general are thinly traded. On the basis of the $4888 \mathrm{BBB}$ bonds that have any trades during the selection period, the average BBB bond trades only 1.4 times per day, and on average no trades occur at all on almost three quarters of the sample period days for these bonds. The table also summarizes that trading tends to occur in temporal clusters, as the mean of the average time between trades is about 15 days, while the median is half that (7.3 days). This may be due to dealers' desire to maintain low inventory positions in bonds that are thinly traded, causing them to quickly sell a bond they have recently bought from a customer. ${ }^{9}$

The trading activity statistics for the 90 disseminated bonds and the matching nondisseminated bonds also show a close match. The median average daily volume is 1499 for the 90 disseminated bonds and 1427 for the nondisseminated matching bonds. Matching even closer are the median average daily trade count ( 1.0 for both the 90 disseminated bonds and the 90 matching bonds), the percent of days traded (39.5\% for the disseminated and $39.9 \%$ for the matching bonds), and the average days between trades (3.6 for both groups). Both groups are noticeably more active than the bonds in the nondisseminated control portfolio. ${ }^{10}$ Turning to the 30 thinly traded bonds, the dollar volume of trade for bonds in their nondisseminated control portfolio is lower than for the 30 disseminated bonds, but the trading activity is otherwise similar.

\section{Effect of Increased Transparency on Trade Frequency and Trading Volume}

In this section, we measure the impact of transparency by analyzing the change in the level of trading activity before and after the bonds become transparent in April 2003. As discussed above, it is not clear whether the introduction of transparency will be associated with an increase or with a decline in this measure of liquidity. We consider two measures of trading activity: average daily trading volume and average number of trades per day. To allow time to adjust to the new reporting regime, we exclude the two-week period surrounding the start of dissemination of data. All

\footnotetext{
${ }^{9}$ This possibility is further explored in Section 3.3.

${ }^{10}$ The distribution of trading frequency across all 4888 BBB bonds is highly skewed toward less actively traded bonds. Our 90-bond sample, however, selects bonds more uniformly from the distribution so that we can observe the impact of transparency across the full range of trading frequency. As the control portfolio reflects the actual distribution of trading activity, it contains relatively more bonds that are less active than those in the disseminated bond sample.
} 
results in this and the following sections are similar when we restrict our analysis to the six-month window surrounding the April 14, 2003 start of dissemination.

Table 3 reports the changes in average daily trading volume (panel A) and average number of trades per day (panel B). Panel A shows that trading volume falls for both the disseminated and the nondisseminated bonds from the opaque to the transparent period. The volume drop of roughly $30-40 \%$ is both statistically and economically important. To test whether this drop is related to the change in transparency, we adjust the changes for the disseminated bond groups by the change in trading activity for the corresponding nondisseminated controls. The $t$-statistics show that almost none of these "difference of differences" are significant. Only the drop in the average daily trading volume for the 90 disseminated bonds relative to the nondisseminated control portfolio is statistically significant, indicating that volume decreases relative to this control group. ${ }^{11}$ Similar outcomes are shown in panel B for the trade count measure; the declines observed for the 30 bond sample are somewhat smaller, but the difference of differences are still generally insignificant. ${ }^{12}$

A downward trend in volume over this time period is also apparent from Figure 1, which plots by month the sample average of average daily trading volume for each bond group. For comparison, we also plot the average daily trading volume for BBB bonds with issue size greater than $\$ 1$ billion; these bonds are otherwise excluded from our analysis because they are transparent throughout this time period, yet they also show declining volume. This evidence suggests that the declines in trading volume reported in Table 3 reflect an overall market trend and are not directly related to a change in transparency.

Although we cannot attribute changes in aggregate bond volume to increased transparency, it is possible that investors, rather than dealers, are drawn to bonds with higher transparency. Table 4 considers this possibility by repeating the analysis but excluding all inter-dealer trades. The table is analogous to Table 3 and most results are similar. Both panels indicate that there is no change in trading activity at conventional levels of significance that is related to the increase in transparency. We also examine (not reported) the change in volume of large trades and of

\footnotetext{
${ }^{11}$ This univariate result, however, is not supported by the multivariate regressions summarized in Table 5 .

${ }^{12}$ We also find results consistent with those reported when we examine the change in volume and trade count of individual disseminated bonds. Trading volume increases for 30 of the 90 disseminated bonds, whereas trade count increases for 27 bonds. Similarly, when compared with their individual matchers, 52 disseminated bonds have a relative increase in trading volume and 40 bonds have a relative increase in trade count.
} 


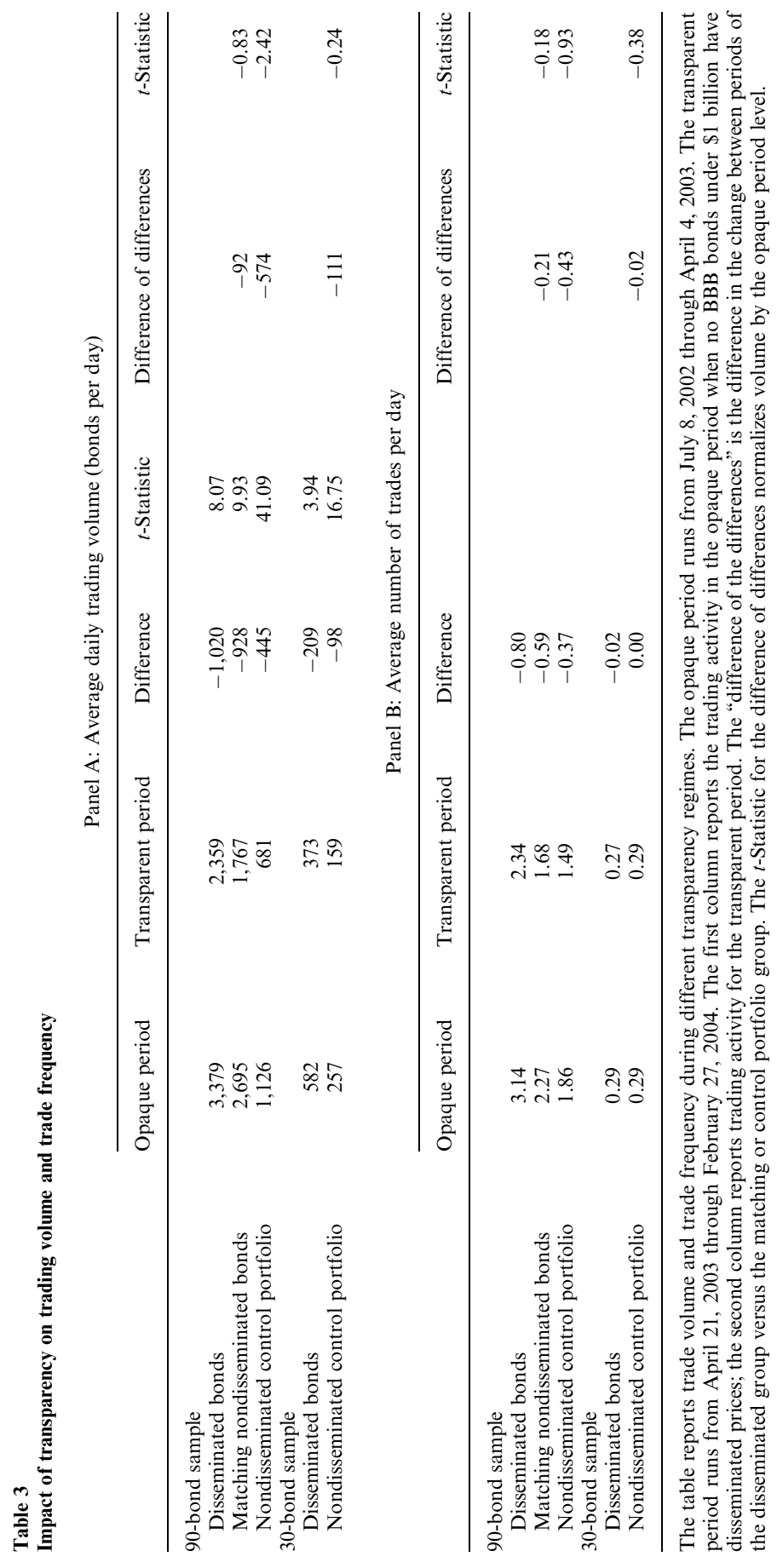



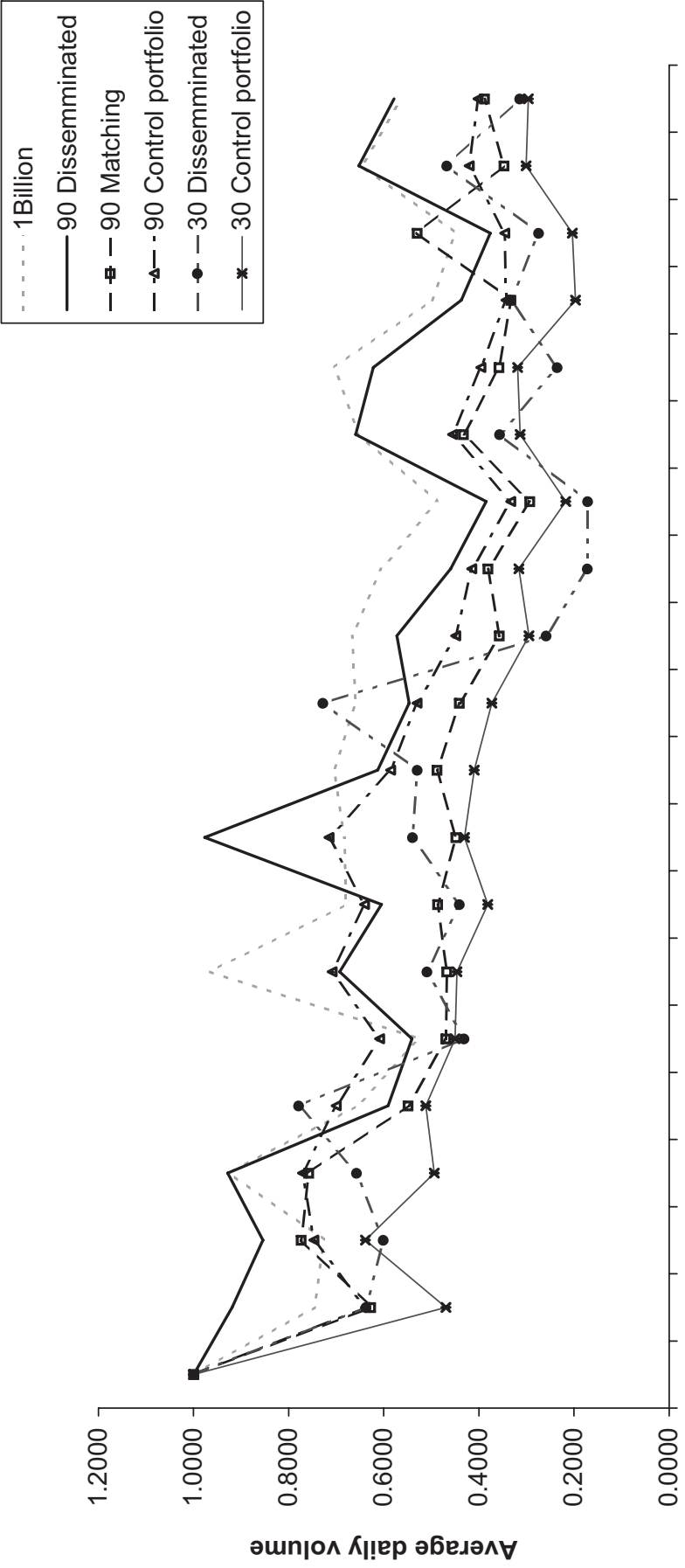

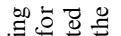

을 응

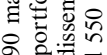

잉유

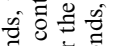

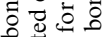

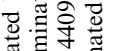

范

总

๙워

플

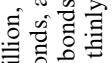

尚完客

跐戸

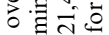

的总怘令

त्च छे

\&

늟 웡요

형ㅎㅁ

च웜웅

$8 / 5$

$8 / 8$

ही

8/

$8 / 2$

$\vec{O}^{2 / 2}$

$C_{0 / 2}$

$\mathrm{C}^{\circ}$

का/

$2 / 0$

$\mathrm{C}^{2}$

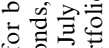

유욤

응응 웅

응흥

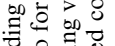

붕

중율

品

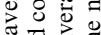

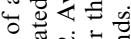

品家。

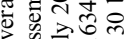

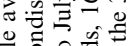

II

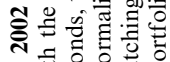

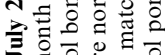

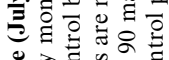

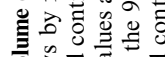

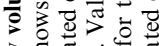

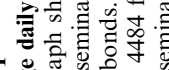

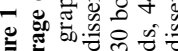

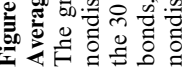




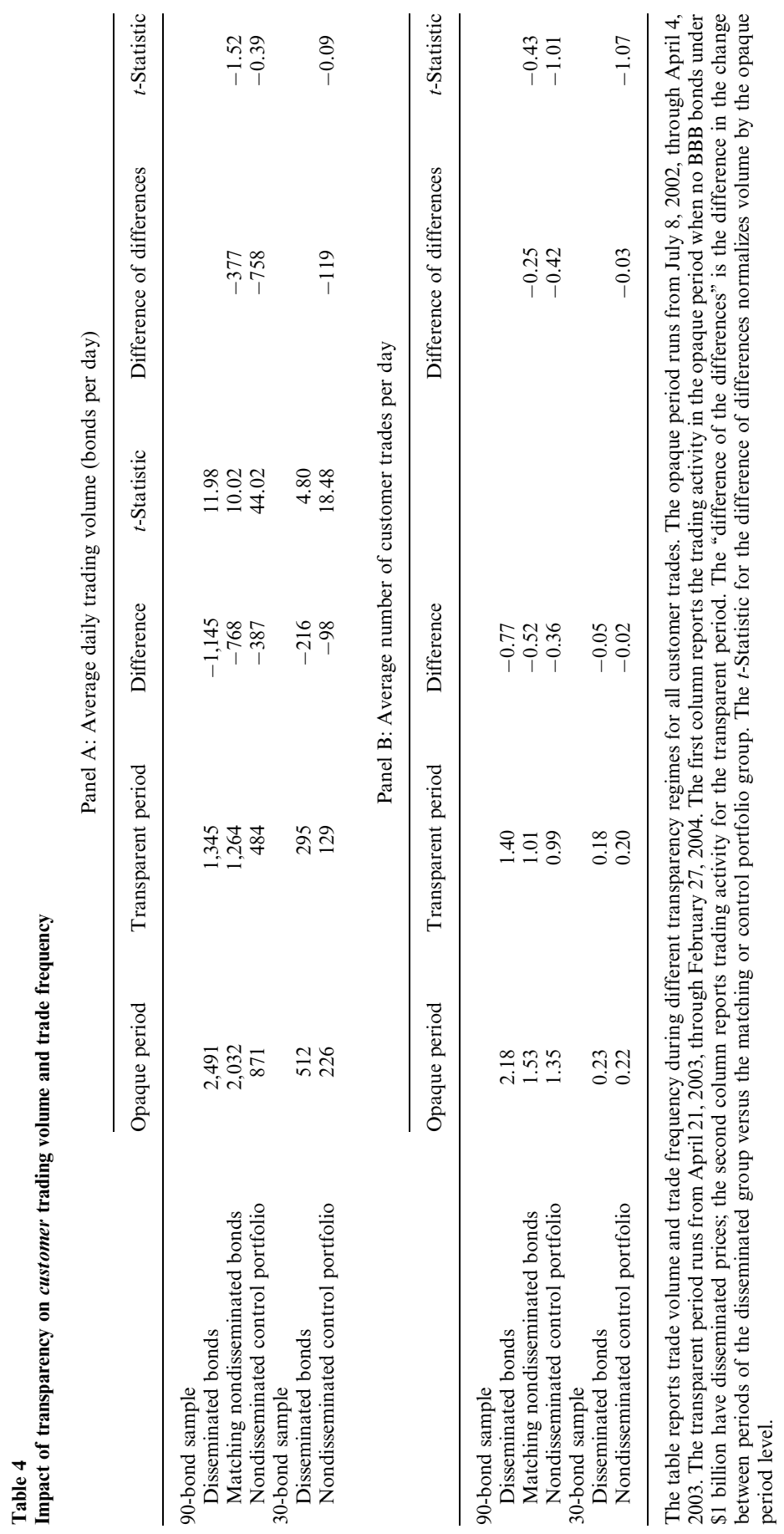


small trades (less than 100 bonds); in fact, the distribution of trade sizes is quite similar across the two time periods. ${ }^{13}$

The above results indicate no measurable effect of increased transparency on these two trading activity measures of bond liquidity. However, it is possible that changes in liquidity are related to other traits of the bond. Although our sample of 90 matching nondisseminated bonds controls for some of these characteristics, the control portfolios are created based only on trading frequency and so do not. We therefore use a multivariate regression to test whether increased transparency is related to changes in bond trading activity, controlling for cross-sectional differences in bond characteristics. The results of the regression are summarized in Table 5. The independent variable in the regression is either average daily trading volume or average number of trades per day.

For the 90 disseminated bonds and their 90 matchers, bonds from larger bond issues have higher trading volume than bonds from smaller issues. Bond age is significantly negatively related to trading volume, as in the findings of Hotchkiss, Jostova, and Warga (2005). The coefficient on the postdissemination period indicator is negative and significant at the $5 \%$ level, consistent with our univariate result that volume dropped for the later period. However, the key variable of interest is the interaction variable for disseminated bonds in the postdissemination period. The coefficient on this interacted variable is statistically insignificant. Similarly, no effect is found for the change in average daily trade count.

This result is born out for the other bond groups as well. In fact, across all six regressions in Table 5, the coefficient on the disseminated bond in the postdissemination period is significant only for the average daily volume regression for the 30 thinly traded bonds and their control sample, and then only at the $10 \%$ level. Taken together, this and the two preceding tables lead us to conclude that there appears to be no significant change in volume for BBB bonds that can be attributed to an increase in last-sale transparency.

The fact that we do not observe an increase in volume with the introduction of transparency is particularly interesting because we simultaneously observe a decrease in spreads for this market, as we show in Section 3 below. Models such as Harris's (1994) imply that volume will increase if spreads decrease. Finding that there is no significant change in volume despite a decrease in spreads is consistent, however, with many empirical studies of more direct spread reductions in equity markets (which also found no volume effects). For example, Ahn, Cao, and Choe (1996) examine the ASE's 1992 tick size reduction on low priced

\footnotetext{
${ }^{13}$ For example, for both the 90 disseminated bonds and 90 matchers, approximately $55 \%$ of trade count in both periods is because of trades of 50 bonds or less (retail-sized trades); these smaller trades however account for about $1 \%$ of the face amount of bonds traded.
} 


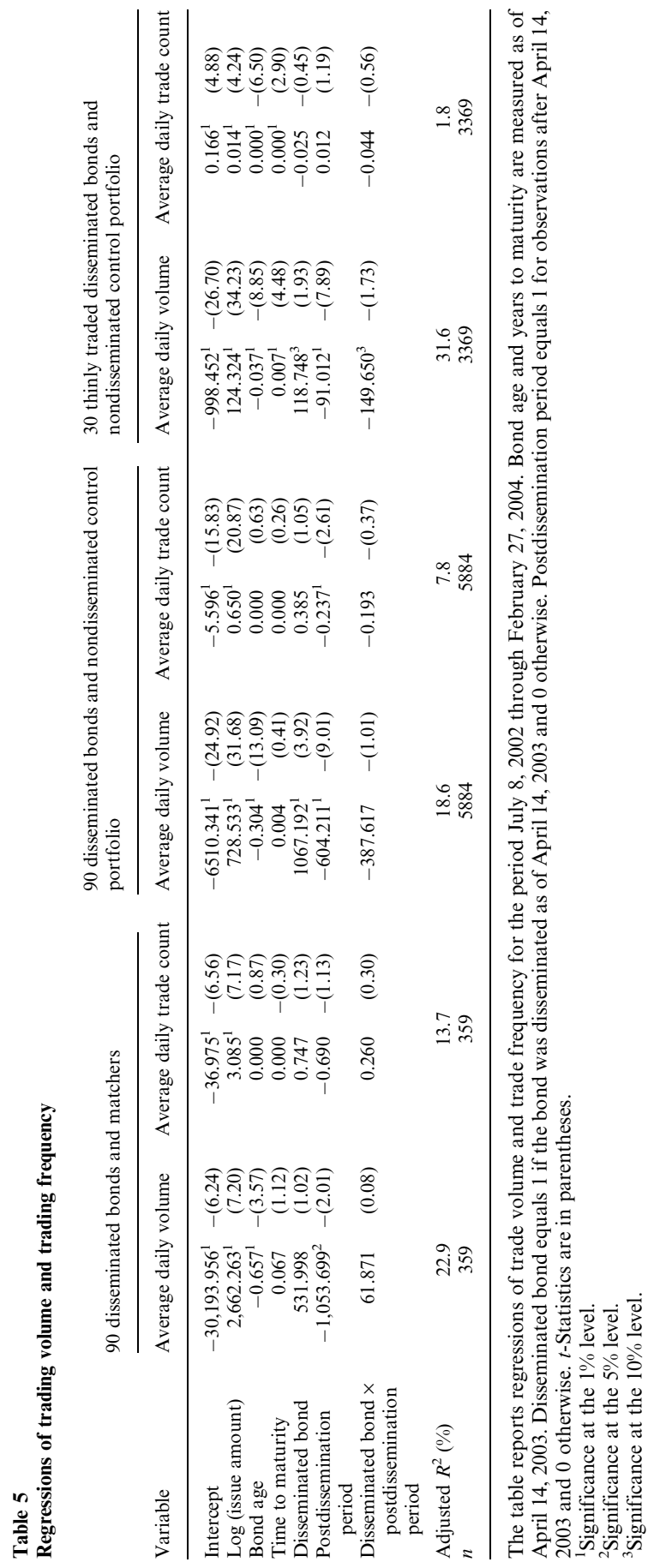


stocks; although they find that spreads fell significantly, they find no effect on the number of trades or volume. Similar results are found by (i) Bacidore (1997) for the reduction in tick sizes on the Toronto Stock Exchange (TSE); (ii) Ahn, Cao, and Choe (1998) in their study of decimalization on the TSE; (iii) Ronen and Weaver (2001), who examine the ASE tick size reductions; and (iv) Chakravarty, Wood, and Van Ness (2004) in their examination of the NYSE's reduction of its minimum price increment. Consistent with our results, these articles demonstrate across a number of markets that a reduction in spreads is not associated with a change in trading activity.

\section{Effect of Increased Transparency on Trading Costs}

Although transaction costs can have multiple components, perhaps the most important for our purposes is the effective spread of the bond. This is the difference between what a customer pays when they buy a bond and what they receive if they sell the bond. The price difference is related to the dealer markup or profit on the trades. We prefer the term "spread" as markups can take on certain regulatory implications.

Section 3.1 reports estimates of spreads directly based on DRT trades. Section 3.2 reports regression-based spread estimates using benchmark prices obtained from a third party data source (Reuters). Section 3.3 further examines the relation between spreads, trading activity, and transparency.

\subsection{Estimation of spreads from DRT trades}

We take as a measure of transaction costs the difference between what a customer pays and receives for a fixed quantity of a bond. We estimate this measure by identifying instances where an individual dealer acquires a bond from a customer and then that same dealer subsequently sells the same bond to a different customer. By restricting the time between these two trades to be sufficiently short (e.g., one day or five days), factors such as interest rates and credit quality are unlikely to change; the difference in these two prices is then the effective spread of the bond. ${ }^{14}$ Lengthening the round-trip window permits exogenous factors to affect dealer spreads but allows more trade observations to enter our sample.

Table 6 reports the distribution of these spreads for all principal trades that qualify as part of a DRT for the 4888 bonds in our sample. The table reports results by ending trade size bins and for each bin gives the mean spread and various percentile points of the spread distribution. Panel A places no time restriction on the DRT. Noticeably, spreads are larger for smaller trades. For trades of 10 bonds or less (of which there are 192,277

\footnotetext{
${ }^{14}$ We have also estimated results from more complex transactions such as customer-dealer-dealer-customer chains of trades. Although not presented for the sake of brevity, the results throughout this article are substantively similar. Results are also similar when we include observations of a dealer sale preceding a dealer buy.
} 


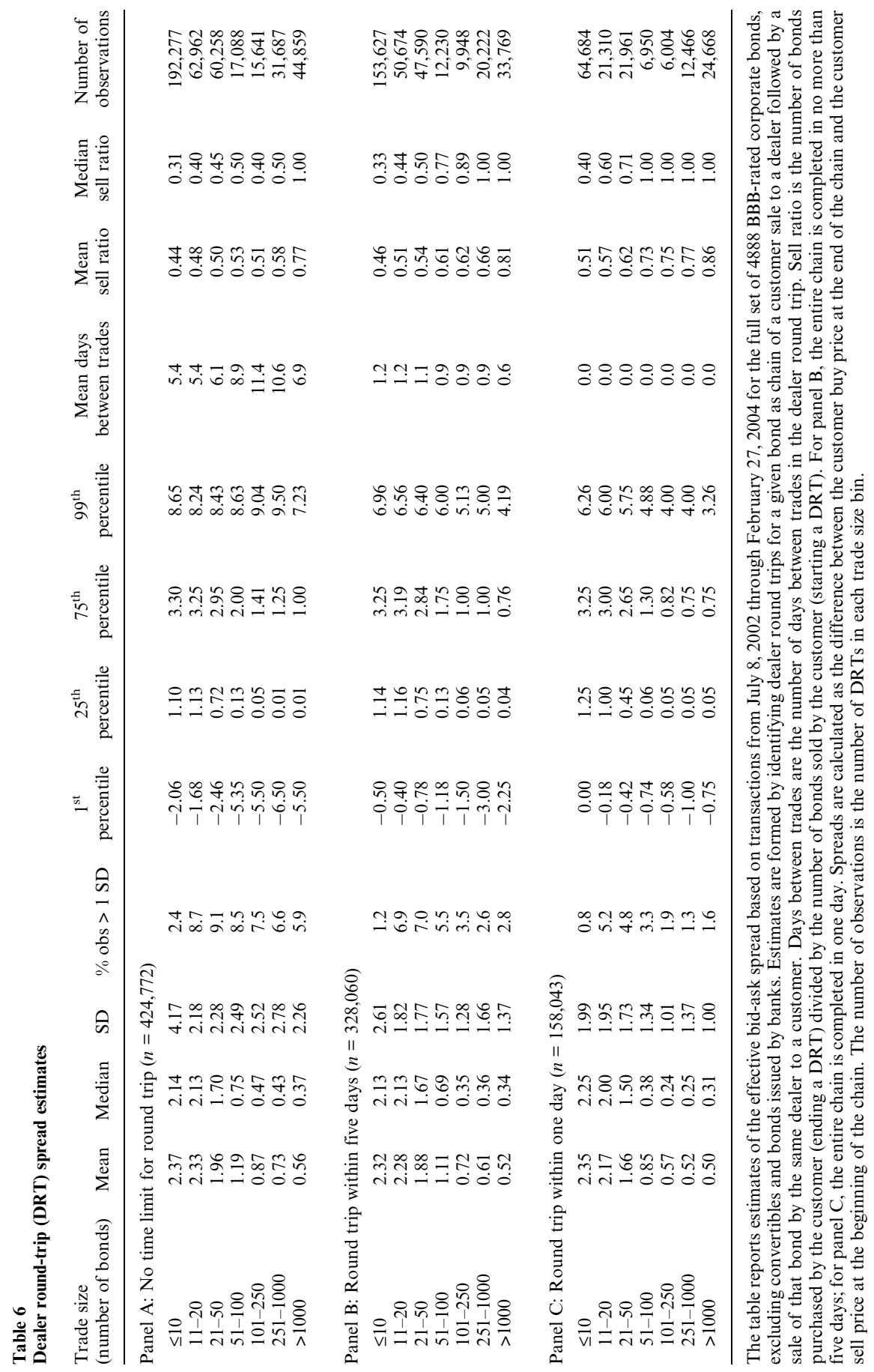


round-trips), the mean cost is $\$ 2.37$ per $\$ 100$ bond face amount. This number reflects a high cost of trading relative to what has been documented in other markets. Given that these small trades involve retail investors, adverse selection should not be an issue. ${ }^{15}$ One important factor explaining these high spreads may be that fixed costs charged to retail customers by their brokers are in turn reflected in spreads, as commissions are not customarily charged on these trades. Still, the standard deviation of spreads is very high, and $25 \%$ of the round-trip trades in this size group have spreads more than $\$ 3.30$.

We also report the mean number of days between trades in the DRT. With no time restriction on the sample, the mean number of days between trades is 5.4 days for smaller trades and is greatest (11.4 days) for trades between 100 and 250 bonds. Overall, 77\% of round-trips are completed within five days (panel B) and 37\% are completed within one day (panel C). As the longer time period allows for significantly more observations, we focus on the five-day round-trips throughout the remainder of this article. However, we have estimated our subsequent tests subject to the requirement that the trades must take place on the same day and find substantively similar results. ${ }^{16}$

While the magnitude of spreads is similar as we restrict the round trip to shorter time intervals, the magnitude of extreme observations is reduced. We also report the mean and median "sell ratio," defined as the ratio of the number of bonds purchased by a customer (ending a DRT) to the number of bonds sold by a customer to a dealer (starting a DRT). The results reported below are qualitatively unchanged when we restrict our sample to observations where the size of the customer purchase is at least $90 \%$ of the size of the initial customer sale (sell ratio is at least 0.90 ).

Table 6 summarizes that spreads fall markedly as trade size increases. Panel B indicates that for institutional trades of over 1000 bonds, or $\$ 1$ million face value, the median cost is only $\$ 0.34$ per $\$ 100$ of face value. This is an $84 \%$ drop from the median cost for a trade of 10 or fewer bonds of $\$ 2.13$ per $\$ 100$. While this is consistent with high fixed costs of trade that are reflected in spreads for small transactions, it could also reflect an uniformed retail investor base that cannot effectively monitor dealer rent

${ }^{15}$ On the basis of the discussions with market participants, it is widely held that trades of fewer than 100 bonds are for retail accounts. This is further supported by analysis done by a large clearing firm, showing that trades of 50 or fewer bonds almost entirely involve retail investors. For our purposes, we assume that trades between 50 and 100 bonds are largely retail but may include some institutional trades.

${ }^{16}$ We perform two checks to verify that our results are not driven by a sample selection effect because of the requirement that the DRT is completed within five days. First, we allow the round-trip time period to range from one day up to five days. The results do not qualitatively change as this time window changes. Second, we re-run the results of Table 6 including only the 48 most liquid bonds in the sample, which trade on $99 \%$ of the sample days. These bonds trade sufficiently often that the round-trip timing requirement will not cause a selection effect, and again, the results are not meaningfully different from Table 6. 
seeking, as in the findings of Green, Hollifield, and Schurhoff (2004). ${ }^{17}$ Also consistent with the findings of Green et al. is our finding that although dealers on average charge lower spreads for larger trades, they are also more apt to lose money on these trades. For example, for trades from 250 to 1000 bonds, a dealer charges on average 61 basis points for the trade but loses 300 basis points or more $1 \%$ of the time. Losses for smaller trades, when they occur, are much smaller.

The magnitude of the measured spreads, in particular for smaller trades, may not be as surprising when one simply looks at plots of transaction prices for a given bond. An example of such a plot for a short time interval is given for one of the 90 disseminated bonds in Figure 2. This bond is in the bottom quartile of the 90-bond sample based on average daily trading volume. The observed price differences on trades occurring on the same or close days are strikingly large, even when we consider that the plot does not control for trade size. These plots also raise two important issues related to outliers in the data. First, when trades can sometimes occur at seemingly large spreads, it becomes difficult to infer whether a trade is a data error or a costly trade. Second, although our test statistics should not be driven by outliers, understanding the presence and behavior of the outliers themselves is an important part of understanding overall behavior in this market.

The magnitude of our estimates can be compared with those of other studies. Edwards et al. (2005), using a different sample of TRACE data, generally report lower trading costs for very small and for very large trades (estimates for intermediate sized trades are closer). For example, their estimate of costs on small trades in BBB bonds is roughly $25 \%$ lower than ours (approximately $\$ 1.50$ versus our estimate of over $\$ 2.32$ for trades of 10 bonds or less). This is true even for the one-day DRTs, for which there is little risk that an event such as a significant interest rate movements could affect our estimates. One potential source of these differences is that Edwards et al. use a two-stage econometric model, in which a cost function is specified and fitted in the first stage. ${ }^{18}$ Another possible explanation is that differences in spread estimates are due to sample differences. Trades that are part of a DRT are likely to reflect more actively traded bonds; we show below in Sections 3.2 and 3.3 that spreads are in fact higher for more actively traded bonds. We address the effect of these selection issues on the magnitude of spread estimates in Section 3.2. Still, for the subset of trades that are part of a DRT, and in particular for DRTs within a short time period, our estimates represent

\footnotetext{
${ }^{17}$ This is also consistent with the model of Bernhardt et al. (2005), which shows that transaction costs and trade sizes are negatively correlated in a dealer market. They provide supporting evidence from the LSE.

${ }^{18}$ Edwards et al. show that the form of the cost function can have a significant effect on spread estimates at the lower end and upper end of trade sizes.
} 


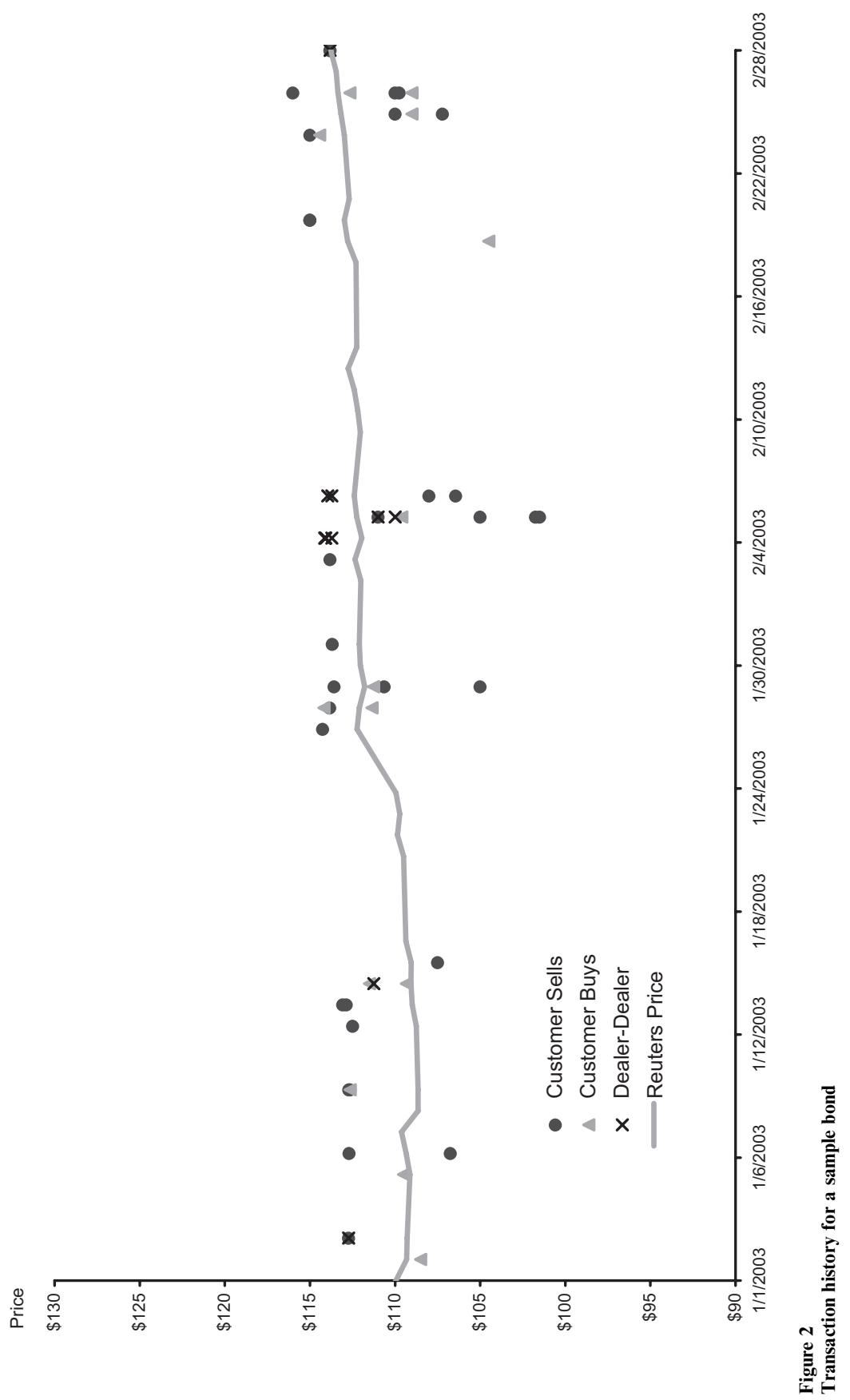


direct observations of the round-trip spread. Bessembinder, Maxwell, and Venkataraman's (2005) post-TRACE cost estimate for large trades (approximately 28 basis points) is closer to ours but includes bonds from other rating categories.

We next apply our method of measuring trading costs to the question of whether liquidity changes when transparency increases. In Table 7, we report spreads separately for DRTs that occur in the predissemination and postdissemination periods. To reduce the influence of outliers, we winsorize our observations for each trade size bin at the 1\% level. Extreme observations of spreads are more likely to reflect instances where other factors, such as a firm-specific event, cause a significant change in the bond's value. We report results only for the 90 disseminated bonds and their control groups; the additional 30 disseminated bonds contribute relatively few DRT observations because of their lower trading frequency.

For the 90 disseminated bonds, there is a significant decrease in the mean and median spread across all trade size groups. For the 90 nondisseminated matchers, we also observe a decline in the mean and median spread, although the significance of these declines is weaker for intermediate sized trades. Finally, for the nondisseminated control portfolio, there is actually an increase in spreads at smaller trade sizes but significant decreases for larger trades. For smaller trades, the mean and median spreads for disseminated bonds are somewhat larger than for nondisseminated bonds, even in the predissemination period.

As in Tables 3 and 4 above, we use a "difference of differences" method to measure the relative change in spreads from the predissemination period to the postdissemination period, controlling for changes in the trading environment. For example, for the 51-100 trade size bin, the mean spread for disseminated bonds decreases by $\$ 0.81$ (from $\$ 1.47$ to $\$ 0.66)$ per $\$ 100$ of face value, whereas the mean for the matching nondisseminated bonds decreases only $\$ 0.26$ (from $\$ 0.73$ to $\$ 0.46$ ). The difference of these differences, 55 basis points, is significant at the $1 \%$ level. Similarly, the mean spread for nondisseminated control portfolio falls only $\$ 0.11$ (from $\$ 1.08$ to $\$ 0.98$ ). Relative to the control portfolio, the disseminated bonds have a decrease in spread of 72 basis points, which is significant at the $1 \%$ level.

The largest relative decline in spreads occurs for intermediate trade sizes. Although we observe a significant increase in spreads relative to the 90 matching bonds for the smallest trade size group (10 bonds or less), this result is not robust to the choice of control group; we observe a significant decline of $\$ 0.28$ relative to the nondisseminated control portfolio. For all other trade size groups, the results based on the nondisseminated control portfolio are consistent with those based on the matching bonds. As noted by Biais and Green (2005), it is difficult to postulate a theory of why, when transparency increases, retail investors would face 


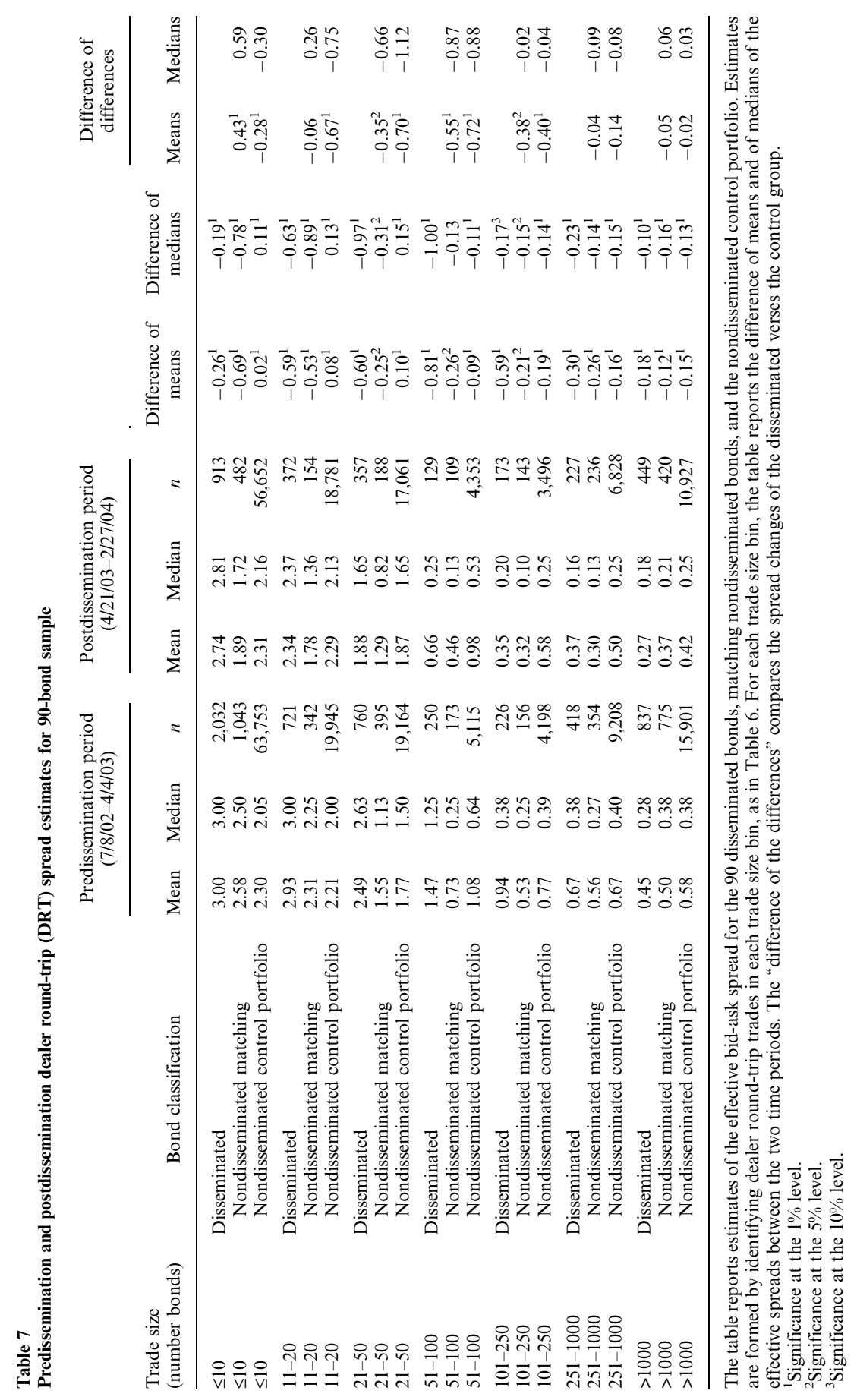


larger trading costs in small information-less trades, especially given that larger trades appear to benefit from the transparency.

Although these univariate results are informative, it is possible that the effects of increased transparency depend on other traits of the bond. To control for cross-sectional differences in bond characteristics, we again use a multivariate regression to estimate whether increased transparency is associated with changes in spreads, controlling for bond characteristics. The results of these regressions are summarized in Table 8 . The dependent variable in the regression is the five-day DRT spread estimate. Table $8 a$ reports results for the 90 disseminated bonds and their 90 nondisseminated matchers, whereas Table $8 b$ reports results for the 90 disseminated bonds and the nondisseminated control portfolio.

The results in these tables are generally consistent with our univariate analysis. From Table 8 ( $a$ and $b$ ), separate from the effects of transparency, the 90 bonds chosen for dissemination have higher spreads than the nondisseminated controls, especially for smaller trades (the coefficient for the "disseminated bond" dummy is positive and significant). For all bonds, spreads fell from the predissemination period to the postdissemination period (the coefficient for the "postdissemination period" dummy is negative and significant). To understand the impact of transparency on spreads, however, the key coefficient is that of the interacted variable, "disseminated bond in postdissemination period." Table $8 a$ indicates a statistically significant relative decrease in spreads when bonds become disseminated for trade sizes from 21 bonds to 250 bonds; the smallest trade size bin (up to 10 bonds) shows a rise in spread consistent with our univariate results. Table $8 b$ summarizes a statistically significant decline relative to the nondisseminated control portfolio for all but the largest trade size groups (251 bonds or more). The impact of transparency appears greatest for intermediate sized trades, with a decline of -0.542 relative to the nondisseminated matching bonds and -0.666 relative to the nondisseminated control portfolio.

The regression results control for the DRT holding period, defined as the time (in days) between the dealer's purchase from a customer and sale to a customer. As this time increases, it is more likely that the spread estimate is influenced by other market events. The positive significant coefficient for this variable may also reflect compensation to dealers for the risk of holding the bond over a longer time period. Interpretation of the other control variables is most useful for Table $8 b$ using the nondisseminated control portfolio, which does not already match bonds based on characteristics. We find that spreads are higher as the interest rate risk (measured by time to maturity) of the bond increases, as the bond ages, and as the issue size falls. We also control for whether a bond has a disseminated "sibling," which occurs when there is another bond of the same issuer with an issue size greater than $\$ 1$ billion. Because bonds over 


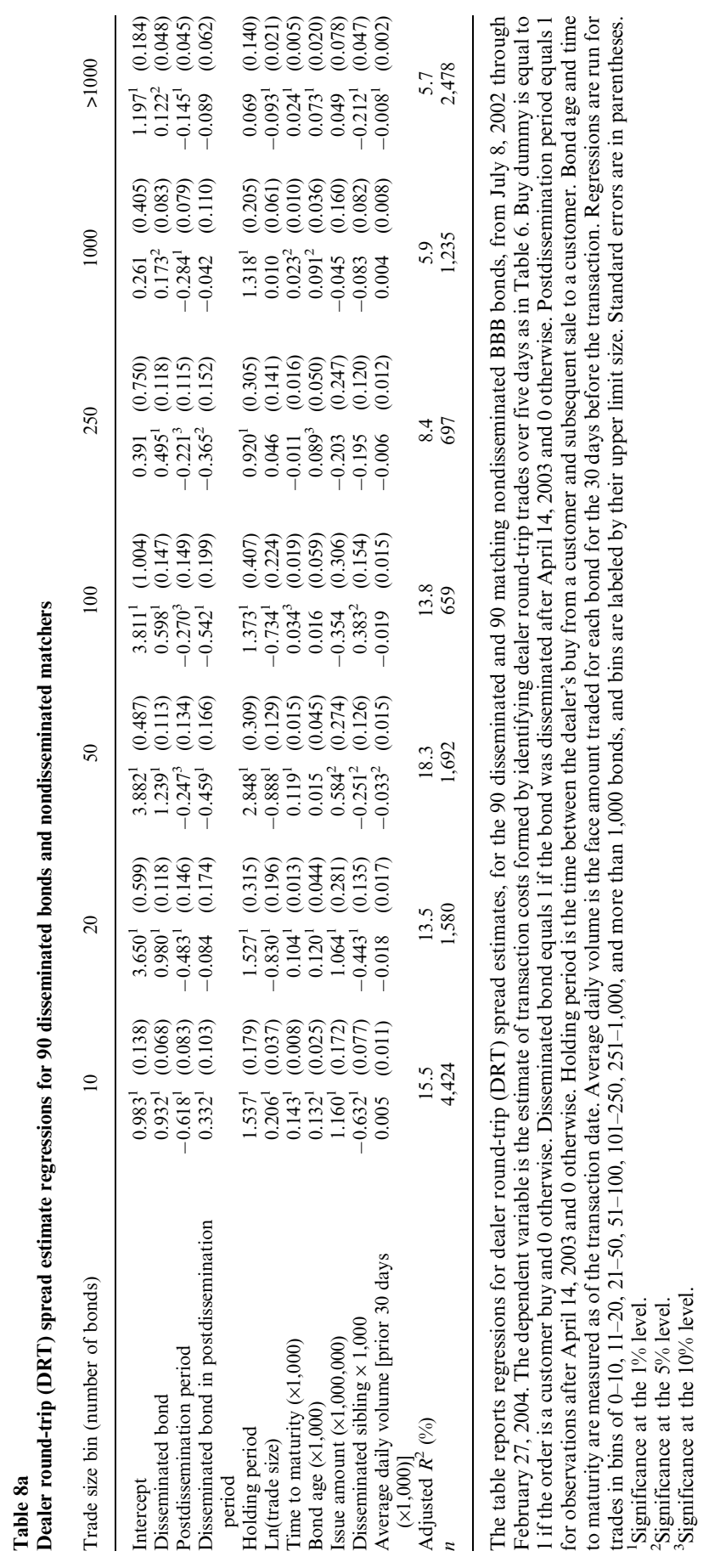




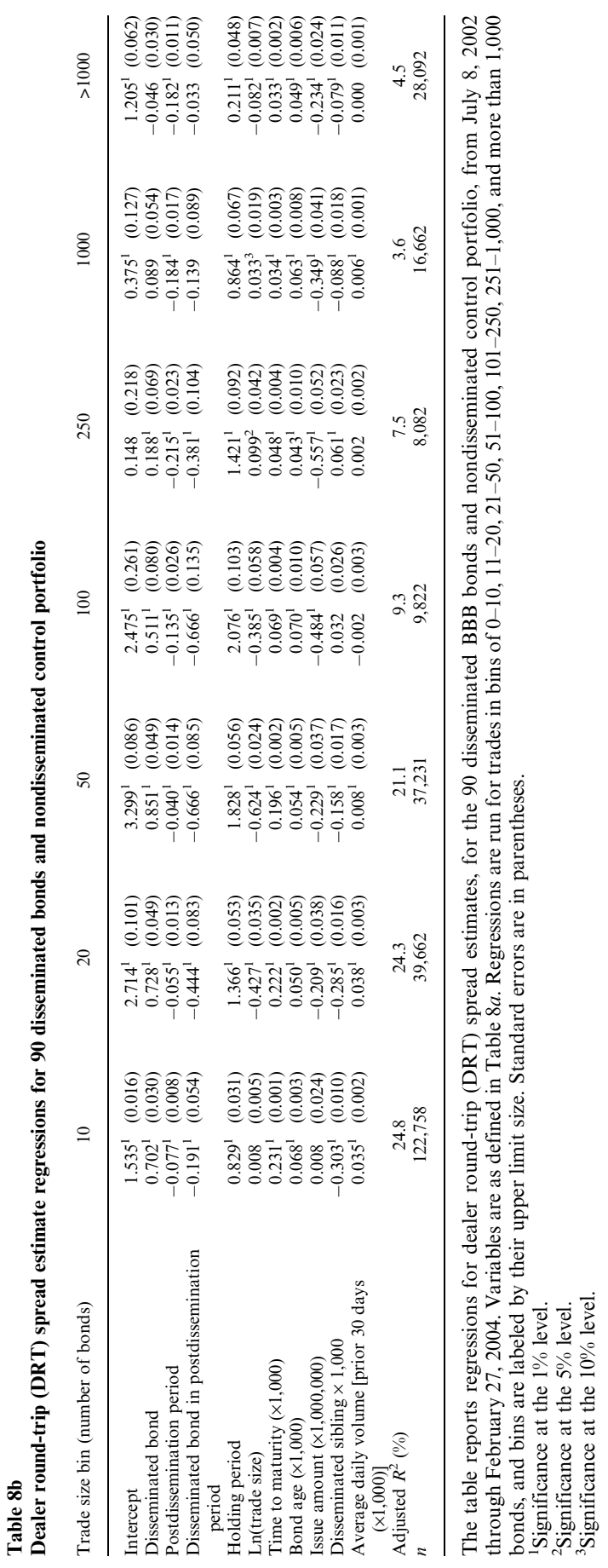


$\$ 1$ billion are also disseminated under TRACE during this time period, such a bond might benefit from the transparency of its larger disseminated sibling. Alternatively, this variable may proxy for larger firms with complex capital structures and thus more public information available and lower trading costs. This effect is most pronounced for smaller trades, where spreads are lower for bonds with disseminated siblings by 30 basis points. ${ }^{19}$ Finally, from Table $8 b$, bonds that have been actively traded in the prior 30 basis points days are also associated with higher trading costs for smaller trades.

\subsection{Regression-based estimates of spreads}

A chief advantage to the estimation method used in the previous section is that it provides a very direct and easily interpretable measure of spreads, using no data external to TRACE and not dependent on assumptions embedded in the modeling of spreads. Its chief drawback is that it only uses a portion of the data available, in that transactions must be part of a DRT as we have defined it. To address this concern, we examine regression-based spread estimates that utilize all of the trading data. ${ }^{20}$ Using this methodology to get an unconditional estimate of spreads comparable with those in Table 6, we estimate effective spreads for each trade size group by regressing the difference between the transaction price for a customer and an estimated bid price on a dummy variable that equals 1 for customer buys and 0 for customer sells:

$$
[\text { customer trade price }- \text { bid price }]_{i}=\alpha_{0}+\alpha_{1} D_{i}^{B u y}+\varepsilon_{i}
$$

We also report a second regression for each trade size group:

[customer trade price - bid price $]_{i}=\alpha_{0}+\alpha_{1} D_{i}^{\text {Buy }}+\alpha_{2} D_{i}^{\text {DisseminatedBond }}$

$$
\begin{aligned}
& +\alpha_{3} D_{i}^{\text {PostdisseminatedPeriod }}+\alpha_{4} D_{i}^{\text {DisseminatedBond } * \text { PostdisseminatedPeriod }} \\
& +\left[\alpha_{5} \ldots \alpha_{10}\right]\left[\begin{array}{c}
X_{5} \\
\vdots \\
X_{10}
\end{array}\right]+\varepsilon_{i}
\end{aligned}
$$

where in addition to the dummy indicating buy transactions, we include a dummy variable indicating disseminated bonds, a dummy variable

\footnotetext{
${ }^{19}$ We also control for whether the bond is displayed on the NYSE's ABS but do not report those results here, as trading on the ABS is relatively more important to the high-yield market. Our coefficient estimates and our conclusions as to the impact of transparency under TRACE are not affected by this additional control variable.

${ }^{20}$ Bessembinder, Maxwell, and Venkataraman (2005) note that their methodology, the methodology of Schultz (2001), and that of Edwards, Harris, and Piwowar (2005) use broadly similar indicator variable regression approaches. The regression-based methodology in this article also falls into this category. A significant difference of the Bessembinder et al. methodology from ours is that they utilize econometric methods to account for the fact that the NAIC data are not time stamped, which is not necessary for the TRACE data.
} 
indicating transactions in the postdissemination period, and the interaction of these two dummies to indicate disseminated bonds in the postdisseminated period. This specification also controls for additional bond characteristics ( $X_{5}$ to $X_{10}$ ) related to spreads. As noted by Schultz (2001), each additional variable is multiplied by +1 for buy and -1 for sale transactions. Results are similar when we do not assume that the spread is symmetric, that is, including separate buy and sell dummy variables.

The difficulty in implementing this approach is that we must use estimated rather than actually observed dealer bid prices. For this study, we use dealer bid prices reported by Reuters for the end of day before the transaction. Reuters bases these estimates on daily quotes obtained from individual dealers and largely does not use matrix prices. ${ }^{21}$ As the bid prices are updated daily by Reuters' analysts to reflect changes in treasury prices, equity prices, and other firm specific information, we do not need additional controls for changes in interest rates and related factors in our regressions. ${ }^{22}$

To eliminate obvious data errors, we exclude observations from our regressions if the difference between the trade price and the Reuters bid price (our dependent variable) is greater than 20. We also winsorize regressions at $1 \%$ within each trade size bin to reduce the influence of outliers. Furthermore, transactions are excluded if the end-of-day Reuters bid price for the transaction date has changed more than $\$ 0.50$ from the previous day's closing bid as reported by Reuters, because in these cases the previous day's ending bid price is less likely to be a useful estimate of the bid quote at the time of the transaction. Results (not reported) are also virtually identical when we include only observations where there is no change in the Reuters bid price between the day before and the day of the transaction.

Table 9 reports the regression-based spread estimates for all principal customer trades in the 90 bonds and their nondisseminated control portfolio. Inferences concerning the impact of transparency are unchanged when we examine estimates (not reported for brevity) based on the 90 disseminated bonds versus the 90 matching control bonds. We report results based on comparison with the control portfolio because it is useful

\footnotetext{
${ }^{21}$ Although there are many outstanding investment grade corporate bond issues, there are only approximately 500 distinct issuers. On the basis of our conversations, Reuters estimates that their analysts obtain direct quotes from dealers for about $85 \%$ of these issuers. Warga and Welch (1993) stress the importance of using dealer bid prices rather than data incorporating matrix prices. For this reason, much prior academic research uses the Lehman Brothers Fixed Income Database, which contains monthly quotes by Lehman Brothers for corporate bonds included in Lehman Indices. Reuters obtains quotes from Lehman and other dealers on a daily basis.

${ }^{22}$ For example, Schultz (2001) constructs estimated bid prices by interpolating between monthly dealer quotes, accounting for changes in treasury prices within the month. Bessembinder, Maxwell, and Venkataraman (2005) include the return on a maturity-matched treasury bond and the return on the firm's equity to control for these movements. These approaches are equivalent to using a matrix price for the benchmark bid price.
} 


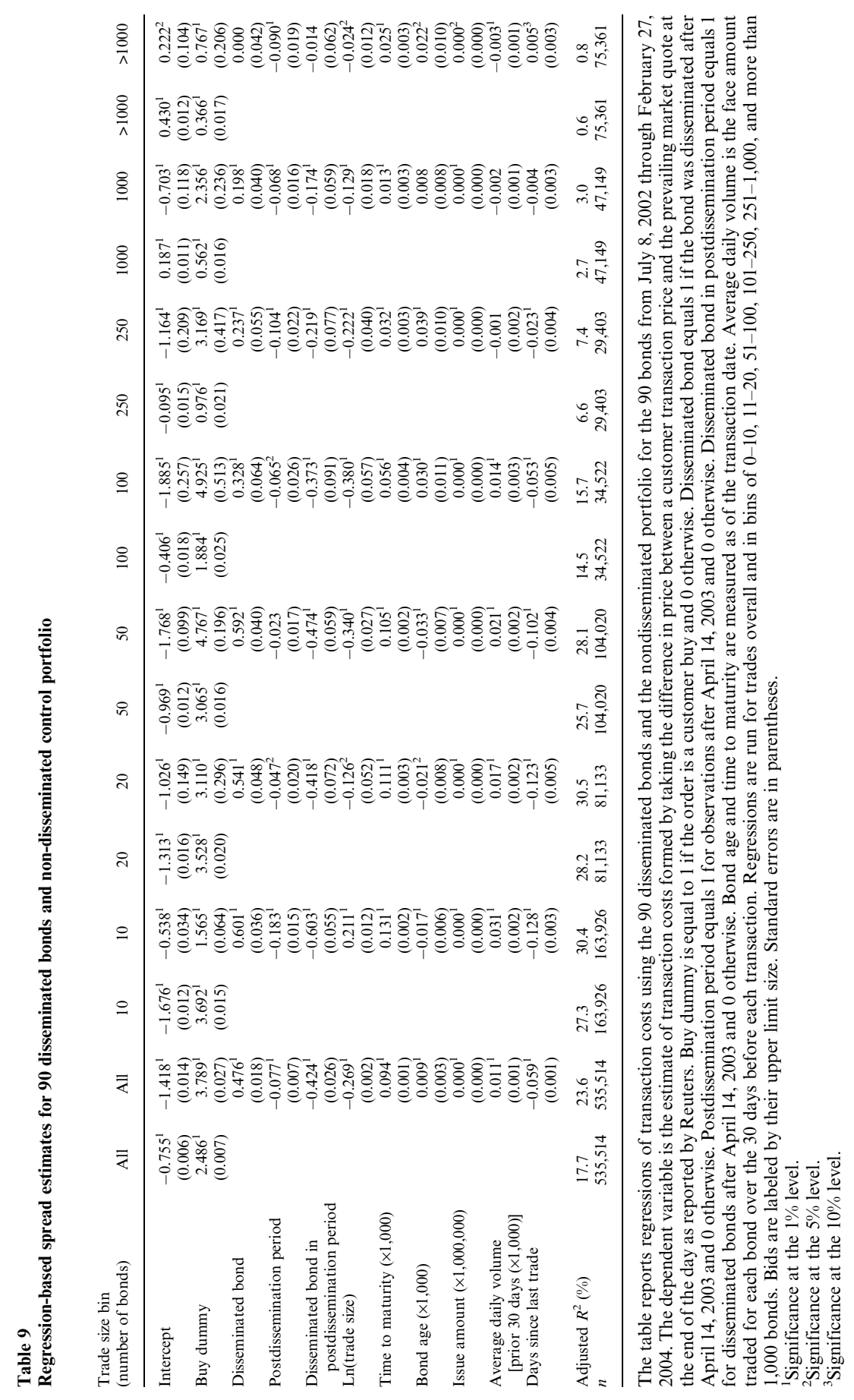


to examine the coefficients of the additional control variables when the control bonds are not already matched on those characteristics.

The intercept in these regressions, $\alpha_{0}$, is the mean difference between the customer sale price and the estimated bid quote. For the full sample under the heading "All," the intercept is negative and significant, but the regressions for trade size groups show that this is largely due to the trades of 250 bonds or fewer. This indicates that for smaller trades, the Reuters bid price is greater than actual customer sale prices. The Reuters prices are largely supplied to the institutional market. Because our estimates also reflect bid prices for smaller retail trades, it is likely that prices obtained by customers on these small customer sales are lower.

The first regression for each trade size group shows the unconditional estimated round-trip trading costs $\left(\alpha_{1}\right.$, the coefficient on the "buy dummy" variable) estimated from Equation (1). We estimate these costs to be $\$ 2.49$ per $\$ 100$ face value overall but find the same inverse relationship with trade size as documented in the previous section. Trades of 10 bonds or less have a spread of $\$ 3.70$, whereas spreads for trades of 1000 bonds or more have a spread of $\$ 0.37$. Interestingly, the regressionadjusted $R^{2}$ s decline substantially for larger trades but do not appear to be related to the number of observations which remains quite large. Our regression-based spread estimates are somewhat higher than those reported using our DRT method. This may be largely because the latter includes only transactions that are part of a DRT. ${ }^{23}$ Furthermore, over a short enough time interval, the DRTs include a large proportion of essentially riskless trades, consistent with the lowered estimated spreads.

The second regression for each trade size group considers the effect of dissemination while controlling for other bond characteristics impacting on spreads. We find that the coefficient on "disseminated bond in postdissemination period" is negative and significant at the $1 \%$ level for all trade size groups except for over 1000 bonds (where it is negative but insignificant) and indicates that spreads are lower when a bond's price is publicly disseminated. The magnitude of this coefficient declines as trade size increases. For example, trades of 10 bonds or fewer show a decline of $\$ 0.60$ per $\$ 100$ face value for bonds that become transparent. ${ }^{24}$ This falls to a $\$ 0.17$ decline for spreads for trade sizes from 251 to 1000 bonds and becomes insignificant for the largest trades. The regression-based results

\footnotetext{
${ }^{23}$ Consistent with this explanation, in robustness, checks not shown here when we use our regression method to estimate spreads using only transactions that are part of a DRT, our regression estimates correspond more closely to those summarized in Table 6 .

${ }^{24}$ The significance of the coefficients for the impact of transparency is also insensitive to the percentage cutoff used to winsorize the dependent variable. However, the magnitude of the coefficients does depend on the method used to reduce the influence of outliers. For example, when we winsorize at $5 \%$, the decline in spreads for the 10 bond or less trade size group is 0.50 (reduced from 0.603 as summarized in Table 9). Generally, removing more extreme observations reduces the magnitude of both the estimated spreads and the dissemination effect but not their statistical significance.
} 
in Table 9, therefore, are consistent with the DRT-based results in Tables 7 and $8(a$ and $b$ ). Collectively, these results on the 90 more actively traded disseminated bonds indicate that spreads fall with increased posttrade transparency.

Table 10 reports a similar set of regressions for the additional 30 disseminated thinly traded bonds and their nondisseminated control portfolio. Interestingly, for trade sizes up to 250 bonds, the spread estimates themselves are somewhat lower for the thinly traded bonds than was estimated for the 90 disseminated bonds and control portfolio in Table 9; for trades sizes of 251 bonds or greater, the estimates are somewhat higher.

A primary concern for the less active bonds is that increased transparency could harm dealers' willingness to commit capital to trade a bond, for fear of having prices fall when the dealer attempts to reposition his inventory. In this scenario, dealers would demand a larger initial price concession from investors, especially at larger sizes, resulting in a higher spread. The results in Table 10 show that this is not the case. The coefficient on "disseminated bond in postdissemination period" is insignificant for all trade sizes. The important result in this table is the lack of support for the hypothesis that investors paid higher costs for thinly traded bonds because of the increased transparency regime.

Overall, we find that the magnitude of the effect of transparency on spreads varies considerably with trade size and also depends on the predissemination level of trading activity for the bond. We find that decreases in spreads range from 0 to 67 basis points. These results can be contrasted with the findings of Edwards et al. (2005), who find that transparency is associated with a drop in trading costs of about 10 basis points (round-trip) across the range of trade sizes, and Bessembinder, Maxwell, and Venkataraman (2005), who find a drop of 12-14 basis points for trades comparable with those in our largest trade size group. ${ }^{25}$

\subsection{Relationship of spreads, trading activity, and transparency effects}

An interesting finding from our spread estimates is that for some trade size groups, spreads appear to increase with the level of trading activity. Comparing the coefficient for the buy dummy in Table 9 (the 90 more active bonds and controls) and Table 10 (the 30 thinly traded bonds and controls), the regression-based estimates of spreads are higher for more actively traded bonds for trade sizes up to 250 bonds.

To examine this result further, we verify that a similar relationship exists between trade activity and the DRT spread estimates within the 90 disseminated bond sample. As noted in footnote 10, we intentionally

${ }^{25}$ As noted above, differences from Edwards et al (2005) may be related either to sample differences or to the smooth cost function that Edwards et al. fit to their data. 


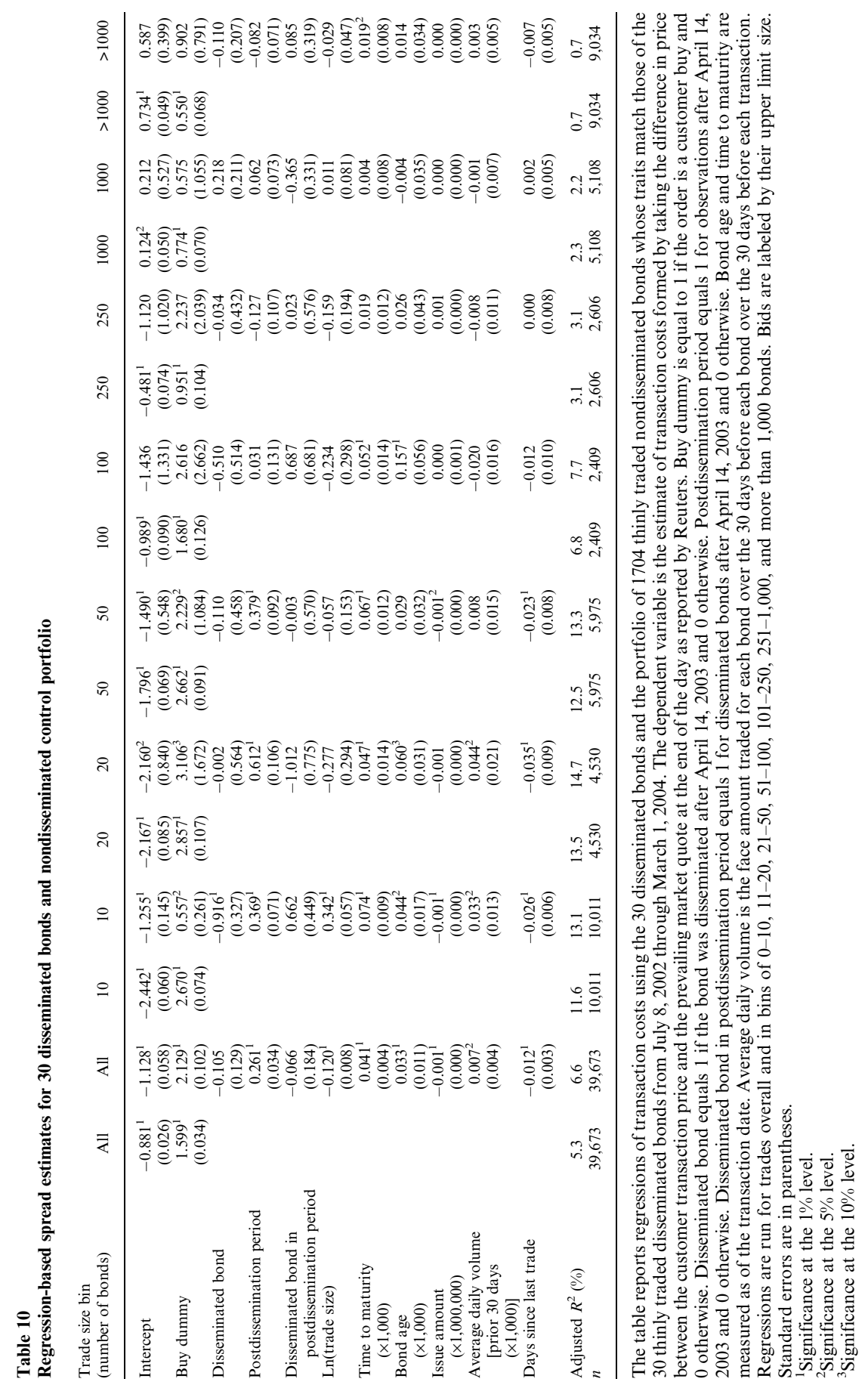


chose our 90-bond sample uniformly across the trading frequency distribution, so that within this group there are more and less actively traded bonds. We therefore divide the 90 disseminated bond sample (and their corresponding matching bonds) into thirds based on the disseminated bond's average daily trade count in the pretransparency selection period and compare the most active 30 bonds with the remaining 60 bonds. We also construct control portfolios for these subgroups such that the average daily trade count for bonds in the control portfolio falls within the range observed for that subgroup. Table 11 reports spread estimates for all bonds in these groups collectively (conclusions are the same looking at the 90 disseminated, matching, and control portfolio groups individually) and summarizes that bonds in the upper third of trading activity have higher mean and median estimated DRT spreads than less active bonds. These results indicate that spread size increases with trading activity not just for the thinly traded bonds but also within the more frequently traded bond groups.

One possible explanation for this finding is that certain bonds become more active in response to some firm-specific information that might also be associated with higher spreads. Another possibility is that dealers trade less active bonds differently than more active bonds. As dealers can more easily find willing counterparties in active bonds, they may be more willing to take these bonds into inventory in their dealer capacity. By definition, it is more difficult to find counterparties with which to trade in less active bonds, so that dealers may perform more of a matching or brokerage function in these bonds. ${ }^{26}$

The evidence in Table 11 is consistent with the latter explanation. For all trade size groups of over 50 bonds, the time between the dealer purchase and dealer sale in the DRT (holding period) is lower for less active bonds. Furthermore, when they do sell, they tend to sell more of their position: the mean and median sell ratios (the ratio of the size of the ending dealer sale to the starting dealer purchase in the DRT) are higher for less active bonds. In other words, when a less active bond is taken into inventory, the dealer more often quickly sells the entire position. ${ }^{27}$ Thus, the lower spreads on less active bonds reflect a difference in dealer behavior. For less active issues, dealers may serve more of a search role, matching buyers and sellers, and not assuming the risk of holding bonds in their inventory. Dealers may also take less profit (providing better prices and hence smaller spreads) to find a willing counterparty more quickly.

${ }^{26}$ Recall that even a relatively active bond, as we have defined it, can trade infrequently relative to most other markets.

${ }^{27}$ We document a similar finding in a related study of spreads in the high-yield bond market. Less active high-yield bonds have lower estimated spreads, but dealer holding periods are lower and sell ratios are higher for these issues. 


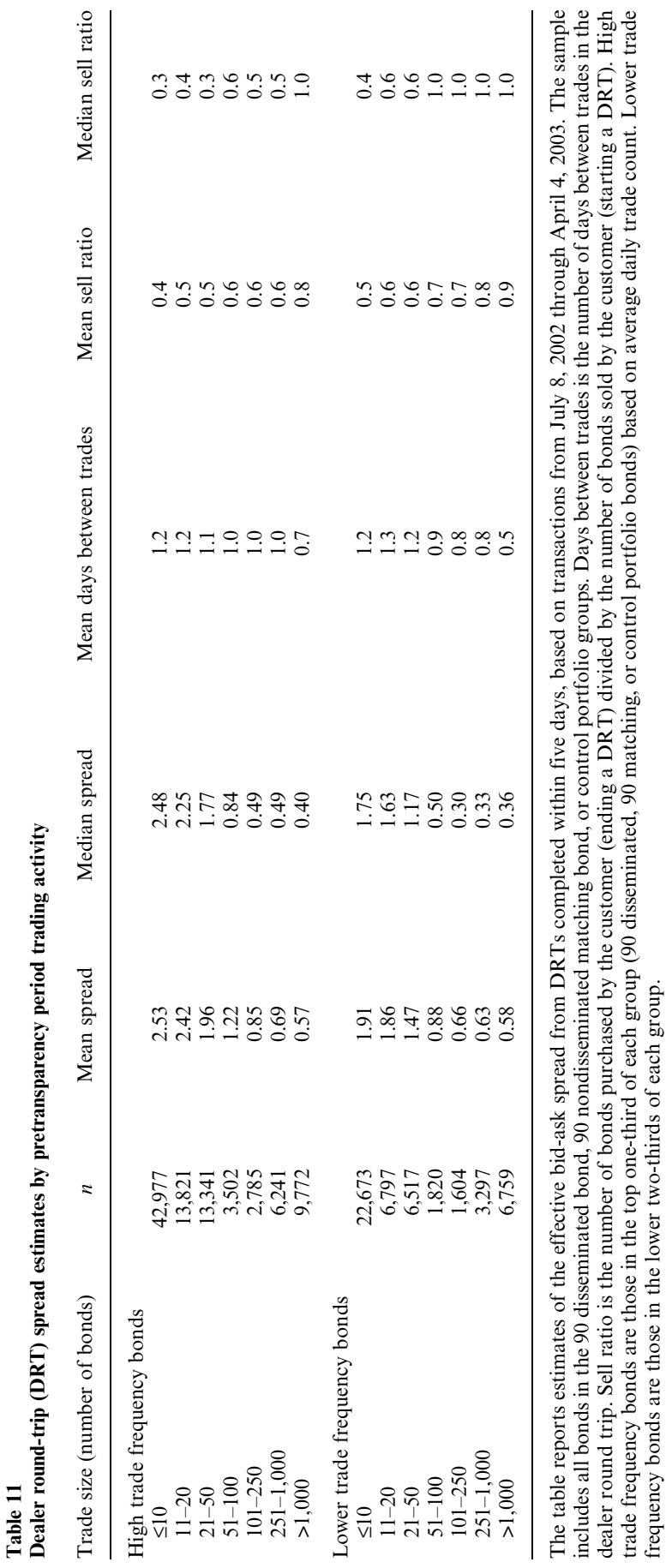


Given that dealers mitigate the risk of holding less active bonds, the effects of transparency may not be as large as originally expected for less active bonds. Furthermore, for inactively traded bonds, the last-sale information that is provided by TRACE could be days or weeks old. Therefore, the additional information provided by this posttrade transparency could be of less value. The results in Section 3.2 support this suggestion in that the reduction in spreads associated with the introduction of transparency is significant only for the 90 more actively traded disseminated bonds and not the 30 thinly traded disseminated bonds.

We explore this result further in two ways, using just the 90 disseminated bond sample and controls. First, we repeat our analysis of regression-based spread estimates as in Table 9 but divide bonds into two groups based on their average daily trade count in the pretransparency selection period. The results (not shown here for brevity) indicate that for trade sizes up to 1000 bonds, the coefficient for the effect of dissemination is greater for the bonds that traded more frequently in the pretransparency period. Second, we repeat the analysis for the full sample of 90 disseminated bonds and controls but add an additional variable to the regressions interacting the dissemination effect with the average daily volume in the 30 days before the trade. The results (also not shown here for brevity) indicate that the interaction variable is significant at the $1 \%$ level for trade sizes up to 100 bonds and ranges from -0.06 for the smallest trade size group to -0.03 for trades up to 100 bonds.

Both sets of results are consistent with our finding that the impact of transparency on spreads is greatest for more actively traded bonds. We also find consistent results when we perform these additional analyses using our DRT estimate of spreads rather than the regression-based estimates. Our evidence suggests that the availability of last trade price information may have little impact on spreads for less active bonds, where the last sale may have occurred days or weeks before and where the dealer may perform more of a search role.

\section{Summary and Conclusions}

This article presents the results of a unique controlled experiment designed to assess the impact of increased transparency on corporate bond liquidity. Examining transactions data for BBB-rated corporate bonds, we investigate how trading volume and round-trip trading costs change when posttrade transparency is introduced into the market by regulatory fiat.

In general, both spreads and measures of trading activity, such as daily trading volume and number of transactions per day, either decline or show no increase. Using two alternative methods, we find evidence that spreads decrease for bonds whose prices become transparent and that this 
effect is strongest for intermediate trade sizes. The decrease in transaction costs for such trades is consistent with investors being able to negotiate better terms of trade with dealers once the investors have access to broader bond-pricing data. We do not find any effect (positive or negative) of transparency for very thinly traded bonds. Overall, our findings indicate that the increased posttrade transparency has a neutral or positive effect on market liquidity.

Structural changes in transparency, such as those that occurred under TRACE, are observed somewhat rarely. In equities markets, there have been a few opportunities to study the impact of changes in pretrade transparency. For example, Hendershott and Jones (2005) show that the availability of quote information is associated with lower trading costs and increased market quality. Other studies, however, produce more mixed results. ${ }^{28}$ Thus, the results produced here for the introduction of posttrade transparency to the corporate bond market appear much more striking than those obtained previously for stocks. This may reflect the fact that the equities markets studied were already quite transparent. Even with the introduction of posttrade transparency, the corporate bond markets still do not have the same degree of transparency as many other markets.

Although the magnitude of our results differ, it is reassuring that the results of our study are consistent with those of Bessembinder, Maxwell, and Venkataraman (2005) and Edwards et al. (2005). Using substantially different methodologies and samples, each of our studies suggests that the introduction of transparency through TRACE is associated with a decline in trading costs for at least some bonds. Regulators have referred to the results of our studies in their evaluation of the impact of transparency on corporate bond markets. ${ }^{29}$

Policy makers should take comfort in the results of the article. There are few instances in the tables above that show any harm to investors from increasing transparency and many examples that show how investors benefit from the change. The earliest adopters of systems providing access to TRACE data were investment professionals rather than retail investors, so that over time there may be more benefit to the retail market. There are well-founded economic models that argue that transparency should lower transaction cost, especially for smaller trades. The results of this study should help to guide the debate over increasing transparency for securities markets.

\footnotetext{
${ }^{28}$ Studies of pretrade transparency for equities include those of Madhavan, Porter, and Weaver (2005) and Boehmer, Saar, and Yu (2005).

${ }^{29}$ See Annette L. Nazareth, Speech by SEC Commissioner, U. S. Securities and Exchange Commission, February 7, 2006; Financial Services Authority, "Trading Transparency in the UK Secondary Bond Markets,” Discussion Paper, September 2005.
} 


\section{Appendix: Data Cleaning and Sample Construction}

Before the inception of TRACE, there was no mandatory reporting of corporate bond transactions. On January 23, 2001, the SEC approved rules requiring NASD members to report over-the-counter secondary market transactions in eligible fixed income securities. These comprehensive reporting requirements apply to investment grade, high yield and unrated debt of US companies, and cover eligible securities including Rule 144A issues, convertible debt, floating rate notes, and various other types of corporate debt. Transactions reports for all eligible securities are reported to the NASD via the TRACE system, which was implemented on July $1,2002 .^{30}$

The initial raw TRACE data set consists of observations for all 4888 TRACE eligible securities with a BBB rating and that traded at least once in the period from July 8, 2002 through January 31, 2003 and did not mature before February 27, 2004. The data include fields for CUSIP, execution date, time, price, yield, quantity, transacting parties' IDs, principal/agent flag, commissions (if applicable), and buy/sell code. For principal trades, the price must include any markups or markdowns. For agency trades, the price does not include the commission charged, because commission is reported in a separate field. The characteristic data include CUSIP, embedded option flags, default status, bond rating, and other characteristic fields. Our analysis includes trades in bonds identified by TRACE as BBB-rated, based on the bond's rating at the time of the trade.

The raw data include observations that contain entry errors, represent duplicate entries, or indicate canceled or corrected trade reports. For example, the trade entry system itself includes checks to screen out data-entry errors for price and yield, and returns an error message when these entries deviate significantly from other recent transactions in the same security. The reporting party can still however resubmit the transaction with an "override flag." To check remaining price errors, we use the median monthly price as a baseline. Prices that exceed the baseline by more than $50 \%$ are divided by an adjustment factor that assumes the price is off either by a factor of 10 or by a factor of 100 . The adjustment factor is assumed to be the multiple that provides an adjusted price closest to the baseline. TRACE guidelines also require users to enter the number of bonds traded; some observations, however, are consistent with users entering the par value of the bonds. Trade quantities that exceed the total number of issued bonds in a particular CUSIP are adjusted by the par value of the issue. All other quantities are assumed to have been entered correctly.

TRACE reporting guidelines result in duplicate entries in our data set for several types of transactions. Because all NASD member firms are required to submit the details for their own side of the transaction, the raw data include two observations for most interdealer trades. To avoid double counting trades, we match both sides of interdealer trades using dealer identities and other trade characteristics. Customer transactions also may have duplicate entries when the member firm acts in an agent capacity and trades on behalf of one of its customers; we match agency trades to remove duplicate entries. Finally, TRACE has specific guidelines as to the entry of certain other interdealer and agency trades; we exclude trades that have entries inconsistent with these guidelines. ${ }^{31}$

${ }^{30}$ As of July 2002, member firms were required to submit reports within one hour and fifteen minutes of trade execution during normal system hours. The reporting window was shortened to 45 minutes on October 1, 2003. See http://www.nasd.com/mkt_sys/TRACE_info.asp for detailed description of the reporting requirements under TRACE.

31 These include incorrect entry of "Give-up" trades and duplicate entries from undisclosed "Automatic Give-Up" trades. 
In addition, a small percentage of trade reports are incorrectly entered into TRACE. All canceled trades are flagged as such and excluded from the analysis. When a user modifies the details of a trade, TRACE creates a new observation that contains all the current terms of the trade, and the original observation is flagged as modified. For those trades that have been revised, we retain the observation with the most recent revision.

\section{References}

Ahn, H., C. Q. Cao, and H. Choe, 1996, "Tick Size, Spread, and Volume," Journal of Financial Intermediation, 5(1), 2-22.

Ahn, H., C. Q. Cao, and H. Choe, 1998, "Decimalization and Competition among Stock Markets: Evidence from the Toronto Stock Exchange Cross-Listed Securities,” Journal of Financial Markets, 1(1), $51-87$.

Alexander, G., A. Edwards, and M. Ferri, 2000, "The Determinants of the Trading Volume of HighYield Corporate Bonds," Journal of Financial Markets, 3(2), 177-204.

Bacidore, J., 1997, “The Impact of Decimalization on Market Quality: An Empirical Investigation of the Toronto Stock Exchange,” Journal of Financial Intermediation, 6(2), 92-120.

Bernhardt, D., V. Dvoracek, E. Hughson, and I. Werner, 2005, "Why Do Larger Orders Receive Discounts on the London Stock Exchange?" Review of Financial Studies, 18(4), 1343-1368.

Bessembinder, H., W. Maxwell, and K. Venkataraman, 2005, "Optimal Market Transparency: Evidence from the Initiation of Trade Reporting in Corporate Bonds," forthcoming in Journal of Financial Economics.

Biais, B., L. Glosten, and C. Spatt, 2005, "Market Microstructure: A Survey of Microfoundations, Empirical Results, and Policy Implications," Journal of Financial Markets, 8(2), 217-264.

Biais, B., and R. Green, 2005, "The Microstructure of the Bond Market in the $20^{\text {th }}$ Century," working paper, Toulouse University and Carnegie Mellon University.

Bloomfield, R., and M. O’Hara, 1999, “Market Transparency: Who Wins and Who Loses?" Review of Financial Studies, 12(1), 5-35.

Boehmer, E., G. Saar, and L. Yu, 2005, "Lifting the Veil: An Analysis of Pre-Trade Transparency at the NYSE," Journal of Finance, 60(2), 783-815.

Chakravarty, S., and A. Sarkar, 2003, "A Comparison of Trading Costs in the U.S. Corporate, Municipal and Treasury Bond Markets," Journal of Fixed Income, 13(1), 39-48.

Chakravarty, S., R. A. Wood, and R. A. Van Ness, 2004, "Decimals and Liquidity: A Study of the NYSE," Journal of Financial Research, 27(1), 75-94.

Chen, L., D. Lesmond, and J. Wei, 2005, “Corporate Yield Spreads and Bond Liquidity,” working paper, Michigan State University, Tulane University, and University of Toronto.

Davies, R., and S. Kim, 2004, "Using Matched Samples to Test for Differences in Trade Execution Costs," working paper, Babson College.

Edwards, A., L. Harris, and M. Piwowar, 2005, "Corporate Bond Market Transparency and Transactions Cost," forthcoming in Journal of Finance.

Federal Register, 2002, Securities and Exchange Commission Release No. 34-47057, File No. SR-NASD2002-174, Vol. 67, no. 249, December 27, FR Doc. 02-32735, P. 79210-79213.

Federal Register, 2003, Securities and Exchange Commission Release No. 34-47566, File No. SR-NASD2003-41, Vol. 68, no. 61, March 31, FR Doc. 03-7613, P. 15490-15492.

Gemmill, G., 1996, "Transparency and Liquidity: A Study of Block Trades on the London Stock Exchange Under Different Publication Rules,” Journal of Finance, 51(5), 1765-1790. 
Green, R., B. Hollifield, and N. Schurhoff, 2004, "Financial Intermediation and the Costs of Trading in an Opaque Market," working paper, Carnegie Mellon University.

Harris, L. E., 1994, “Minimum Price Variations, Discrete Bid-Ask Spreads, and Quotation Sizes,” Review of Financial Studies, 7(1), 149-178.

Hendershott, T., and C. M. Jones, 2005, "Island Goes Dark: Transparency, Fragmentation, and Regulation," Review of Financial Studies, 18(3), 743-793.

Hong, G., and A. Warga, 2000, “An Empirical Study of Corporate Bond Market Transactions," Financial Analysts Journal, 56(2), 32-46.

Hotchkiss, E., G. Jostova, and A. Warga, 2005, "Determinants of Corporate Bond Trading: A Comprehensive Analysis," working paper, Boston College.

Hotchkiss, E., and T. Ronen, 2002, "The Informational Efficiency of the Corporate Bond Market: An Intraday Analysis," Review of Financial Studies, 15(5), 1325-1354.

Madhavan, A., 1995, "Consolidation, Fragmentation, and the Disclosure of Trading Information," Review of Financial Studies, 8(3), 579-603.

Madhavan, A., D. Porter, and D. Weaver, 2005, “Should Securities Markets be Transparent?" Journal of Financial Markets, 8(3), 265-287.

Naik, N., Neuberger, A., and S. Viswanathan, 1999, "Trade Disclosure Regulation in Markets with Negotiated Trades," Review of Financial Studies, 12(4), 873-900.

National Association of Securities Dealers, 2004, Report of the Corporate Debt Market Panel.

Pagano, M., and A. Roell, 1996, "Transparency and Liquidity: A Comparison of Auction and Dealer Markets with Informed Trading," Journal of Finance, 51(2), 579-611.

Ronen, T., and D. G. Weaver, 2001, “Teenies' Anyone?” Journal of Financial Markets, 4(3), 231-260.

Schultz, P., 2001, “Corporate Bond Trading Costs And Practices: A Peek Behind the Curtain," Journal of Finance, 56(2), 677-698.

Warga, A., 1991, “Corporate Bond Price Discrepancies in the Dealer and Exchange Markets," Journal of Fixed Income, 1(3), 7-16.

Warga, A., and I. Welch, 1993, "Bondholder Losses in Leveraged Buyouts," Review of Financial Studies, 6(4), 959-982. 